Portland State University

PDXScholar

Civil and Environmental Engineering Master's

Project Reports

\title{
Evaluation of Truck Signal Priority at N Columbia Blvd and Martin Luther King Jr. Blvd Intersection: VISSIM Micro Simulation Analysis of Truck Signal Priority
}

Maisha Mahmud

Portland State University

Follow this and additional works at: https://pdxscholar.library.pdx.edu/cengin_gradprojects

Part of the Civil Engineering Commons, and the Transportation Engineering Commons Let us know how access to this document benefits you.

\section{Recommended Citation}

Mahmud, Maisha, "Evaluation of Truck Signal Priority at N Columbia Blvd and Martin Luther King Jr. Blvd Intersection: VISSIM Micro Simulation Analysis of Truck Signal Priority" (2014). Civil and Environmental Engineering Master's Project Reports. 5.

https://doi.org/10.15760/CEEMP.31

This Project is brought to you for free and open access. It has been accepted for inclusion in Civil and Environmental Engineering Master's Project Reports by an authorized administrator of PDXScholar. Please contact us if we can make this document more accessible: pdxscholar@pdx.edu. 
EVALUATION OF TRUCK SIGNAL PRIORITY AT N COLUMBIA BLVD AND MARTIN LUTHER KING Jr. BLVD INTERSECTION:

VISSIM MICRO SIMULATION ANALYSIS OF TRUCK SIGNAL PRIORITY

BY

MAISHA MAHMUD

A research project report submitted in partial fulfillment of the requirement for the degree of

\author{
MASTER OF SCIENCE \\ IN \\ CIVIL AND ENVIRONMENTAL ENGINEERING
}

Project Advisor:

Christopher M. Monsere, PhD, PE

Portland State University

(C)2014 


\section{ACKNOWLEDGMENTS}

The author would like to acknowledge the followings for their support in the completion of her Master's Project. I would like to express my sincere gratitude to Dr. Christopher Monsere and Portland State University for their continued support throughout my Master's degree program and during the long road through the completion of this final project. Thanks to Peter Koonce, from City of Portland to help me developing VISSIM model and suggesting the idea for the project. Special thanks to Tom Jensen and Willie Rotich from city of Portland for providing me data, that were needed to develop the VISSIM Model. I could have not completed my degree without the support of my family and most importantly my husband- Thank You. 


\begin{abstract}
Given the importance of over growing freight transportation system worldwide, engineers and planners are faced with the challenge of improving freight service in urban area using low cost measure. Truck Signal Priority is one of the strategy that can be used to improve operational efficiency with enhance safety benefits (red light running) of freight service, without major capital investment. In light to this interest this study focus on evaluating the impacts of freight signal priority on a high truck density intersection like N Columbia Blvd and NE Martin Luther King Jr. Blvd. Using a simulation tool, VISSIM, these impacts were assessed considering a eleven second of green time extension for priority strategy.

Results from this simulation analysis indicated that the given priority from the green time extension strategy in higher truck traffic approach can ensure service reliability, reduce red light running, and improve safety and smoother operations with little to no impact on other vehicular traffic. Overall travel delay and stop delay has improved $13 \%$ and $20 \%$ for truck traffic, while minimum to no impact on travel delay for other vehicles in the approach. Priority also improved carbon emission and reduced pavement damage by reducing trucks stop $9 \%$ to $16 \%$ at major truck moving direction, while minimum or no impact to all vehicles stops in that approach.

This study can serve as groundwork for the evaluation of truck signal priority for agencies and researcher, future research can build upon this effort. Areas identified for future research include the provision of priority on truck leading approach on a coordinated signal system network; testing other priority strategies; combination of emergency preemption and freight preemption; monetary and environmental benefit from priority received network.
\end{abstract}




\section{TABLE OF CONTENTS}

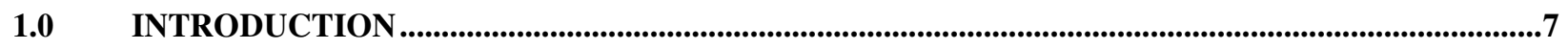

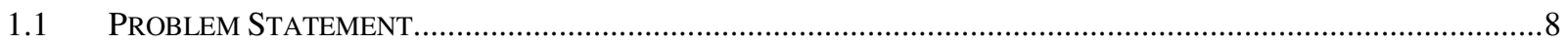

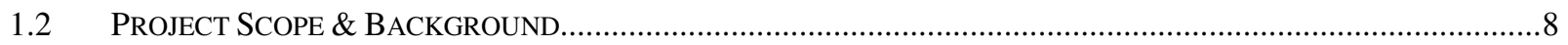

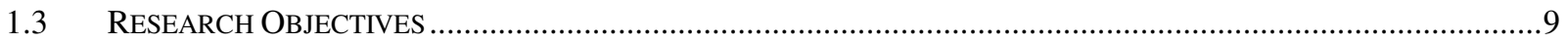

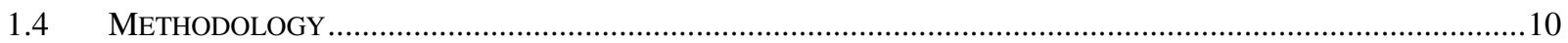

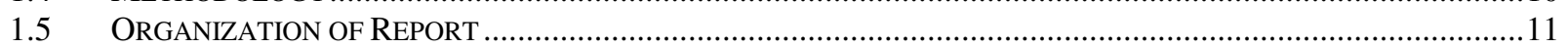

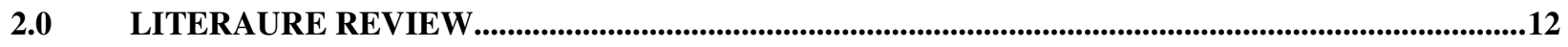

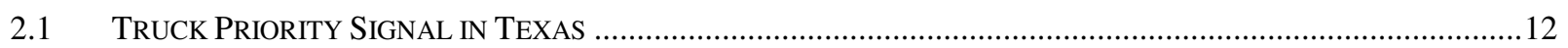

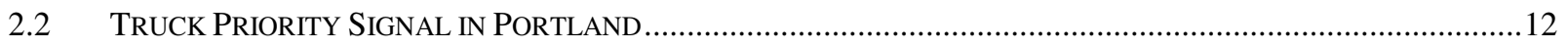

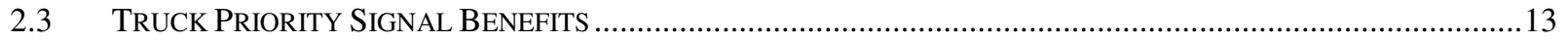

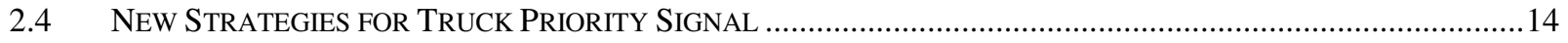

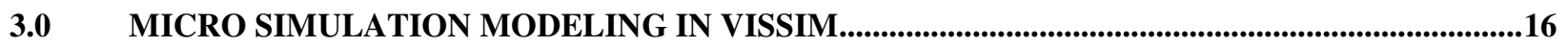

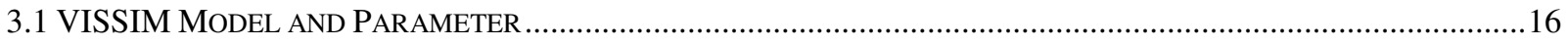

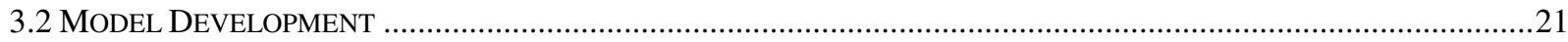

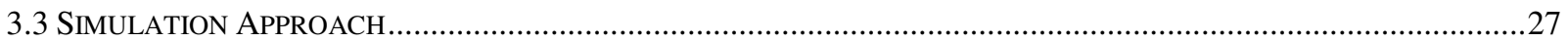

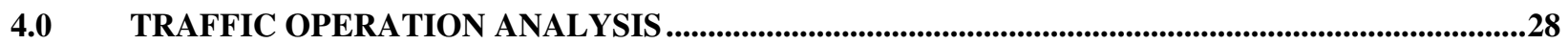

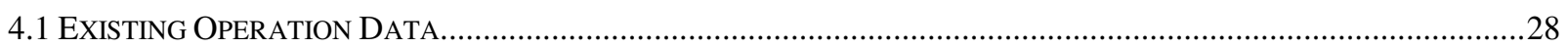

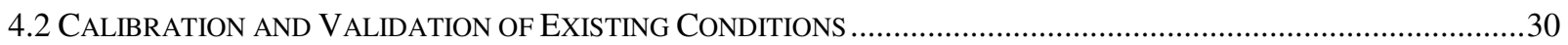

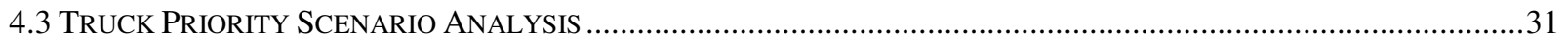

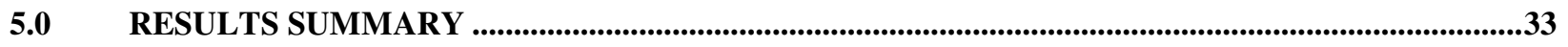

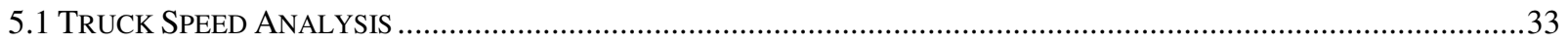

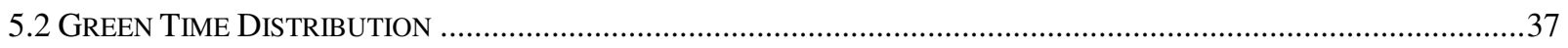

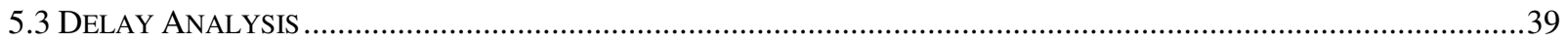

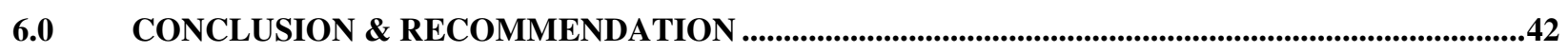

7.0 REFERENCES .......................................................................................................................................44 


\section{LIST OF TABLES}

Table 4.1.1 - Existing Intersection Performances for PM peak and Mid Day Periods..............................................28

Table 4.1.2 - Queue Length Field Count vs. SYNCHRO Model Output................................................................30

Table 4.2.1 - Existing Intersection Delay and Level of Services: Field vs VISSIM Model Output.............................30

Table 4.2.2 - Existing Intersection Queue: Field vs VISSIM Model Output ............................................................30

Table 4.3.1 - Intersection Turning Movement Volumes and Heavy Vehicle Percentages:..........................................32

Table 5.1.1- Total Number of Trucks Not Stopped in the Eastbound Approach.........................................................33

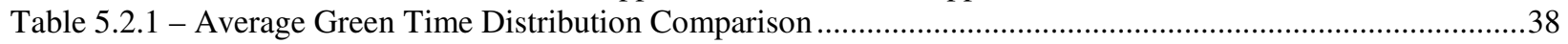

Table 5.2.2 - Average Green Time Distribution Statistics .......................................................................................38

Table 5.3.1 - Average Vehicular Delay Comparison .............................................................................................39

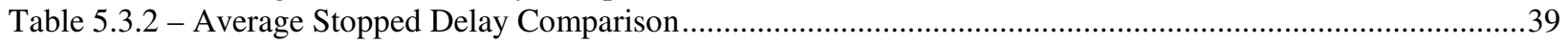

Table 5.3.3 - Average Number of Stops Comparison (Stops/Vehicle) ......................................................................40

Table 5.3.4 - Average Delay and Average Number of Stops Statistics for Eastbound Approach................................40

Table 5.3.5 - Average Delay and Average Number of Stops Statistics for the Intersection ......................................40 


\section{LIST OF FIGURES}

Figure 1: NE Columbia Blvd and NE Martin Luther King Jr. Blvd Intersection ............................................

Figure 2: Communication between traffic simulator and signal state generator..................................................17

Figure 3: Interactive Process of Acceleration and Deceleration of moving vehicles..............................................18

Figure 4: Example of NEMA Signal Controller in VISSIM for Base Signal Coding. ..........................................23

Figure 5: Example of Base Model Setup in VISSIM for the Study Intersection ..................................................25

Figure 6: Example of Truck Priority Model Setup in VISSIM for the Study Intersection. ....................................26

Figure 7: Example of NEMA Signal Controller in VISSIM for Truck Priority Signal Coding. .............................27

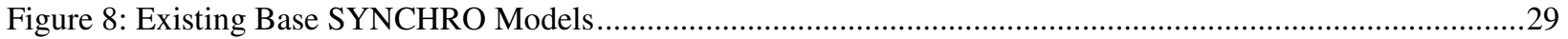

Figure 9: Truck Speed Profiles Base Case (PM Peak Hour) .................................................................................34

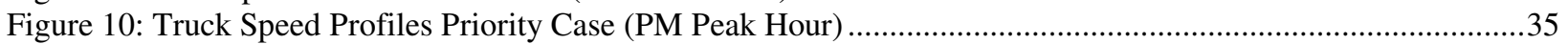

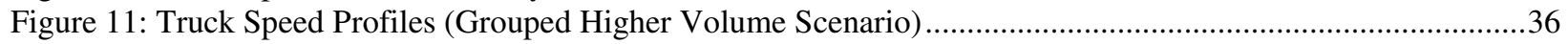

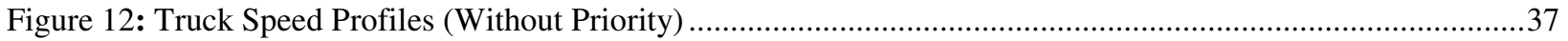




\subsection{INTRODUCTION}

Freight transportation plays a very critical role to fulfill demands of the economic system in the US. The volume of freight movement is growing significantly over the past few decades. According to Freight Analysis Framework (a comprehensive database and policy analysis tool) between the years 1998 to 2020 freight volumes are expected to increase around 70 percent more [1]. In addition to freight growth, Oregon's businesses and individuals are now demanding more flexible and timely service, increasing the importance of an efficient and reliable freight transportation system.

Portland, being a regional hub for the state of Oregon, provides shippers, customers and individual's opportunity for delivering and receiving goods. Despite other transportation modes, the majority of freight moved into, out of, within, and through the Portland region is by truck. According to the Port of Portland's Commodity Flow Forecast, by 2030 truck movement is projected to grow to 73 percent whereas 67 percent of all freight in the region moves by truck at some point in 2000 [2][3]. In Portland's trade dependent economy, the importance of trucking on the region's economic health is paramount and the tonnage volume is expected to increase by 76 percent by 2030 [2]. A recent study found that failure to invest in the region's transportation system will cost the region 6,500 jobs and $\$ 844$ million annually by 2025 - that's $\$ 782$ per household" (Portland Business Alliance, 2006 [4]). This enormous growth in truck traffic is continuously putting pressure on an already congested Portland's highway system. To close this gap between demand and capacity, decision makers are seeking help from new technologies like intelligent transportation system (ITS) for quantifying and increasing the reliability of travel times and also managing the existing infrastructure intelligently. An ITS technology called signal control strategies, can be adapted to various traffic and user conditions and have potential to increase reliability, in addition to improving other measures of effectiveness such as delay, fuel consumption, vehicle operating costs, and safety. Given the importance of the freight transportation system and the limited urban space availability for the expansion of the Portland's transportation network, it is becoming essential to take advantage of state of the art ITS technologies to improve the operation of the existing infrastructure and promote efficient and safe movement of freight traffic. 
Truck Signal Priority (TkSP) is one of the methods that can be used to improve the efficiency and safety of freight movement without major capital investment. A TkSP strategy in a signalized intersection gives priority to the truck traffic when they are detected in the approach. By implementing a TkSP strategy, the truck travel time can be decreased and consequently the cost of goods movement reduced. In addition, there are safety benefits from reducing the number of stops of trucks approaching the intersection at the end of the green phase, which may reduce red light running. Reducing the number of stops for trucks should also have a positive effect on emissions, noise and pavement damage. Finally, it may be used to encourage trucks to use specific routes.

\subsection{Problem Statement}

Smoother operation of freight traffic is critical to the nation as well for the state economy and plays significant roles on mobility and congestion. Trucks are key freight carrier in the US, and operate with a wide verity of loading. Acceleration and deceleration characteristic of truck varies significantly due to its weight. Heavy truck traffic into a corridor reduces mobility, impose severe pavement damage and expose greater safety hazards to the users. At a signalized arterial, frequent stop at red light and fail to stop at red light (red light runner) of heavy vehicles causes severe pavement damage and high accidents. For this study a major freight moving intersection was identified, where freight movement causes severe pavement damage and posse's high safety hazards to the users. To improve safety and reduce pavement damage, this study focused on a technology based solution to evaluate potential operational strategies.

\subsection{Project Scope \& Background}

The City of Portland, in collaboration with Portland State University has identified two potential sites, one at $\mathrm{N}$ Columbia Blvd and $\mathrm{N}$ Macrum Avenue intersection and the other one at $\mathrm{N}$ Columbia Blvd and NE Martin Luther King Jr. Blvd intersection for implementing TkSP strategy. The two potential sites were selected based on two different traffic environments, one with high-speed, low cross street traffic intersection and the other one with heavy traffic, lowspeed intersection. The intent of the TkSP strategy on the study intersections is to distinguish traffic and provide benefit to vehicles depending on the prevailing traffic conditions. As mentioned in the research objectives section that City of Portland has already implemented TkSP 
on N Columbia Blvd and N Macrum Avenue intersection, which was high-speed with low cross street traffic intersection. The N Columbia Blvd is the major freight corridor running east-west direction and NE Martin Luther King Jr. Blvd is a major arterial running north-south direction. Figure 1 in this report showing more details of the study intersection. With this setting the study intersection became a suitable candidate for TkSP evaluation for heavy traffic with low speed intersection. The TkSP implementation on the study intersection is scoped but not limited to following benefits.

- Improve the management and operation of freight traffic in urban corridor.

- $\quad$ Provide better understanding of how Freight interacts with other traffic.

- Incorporate that understanding into an analytical assessment tool.

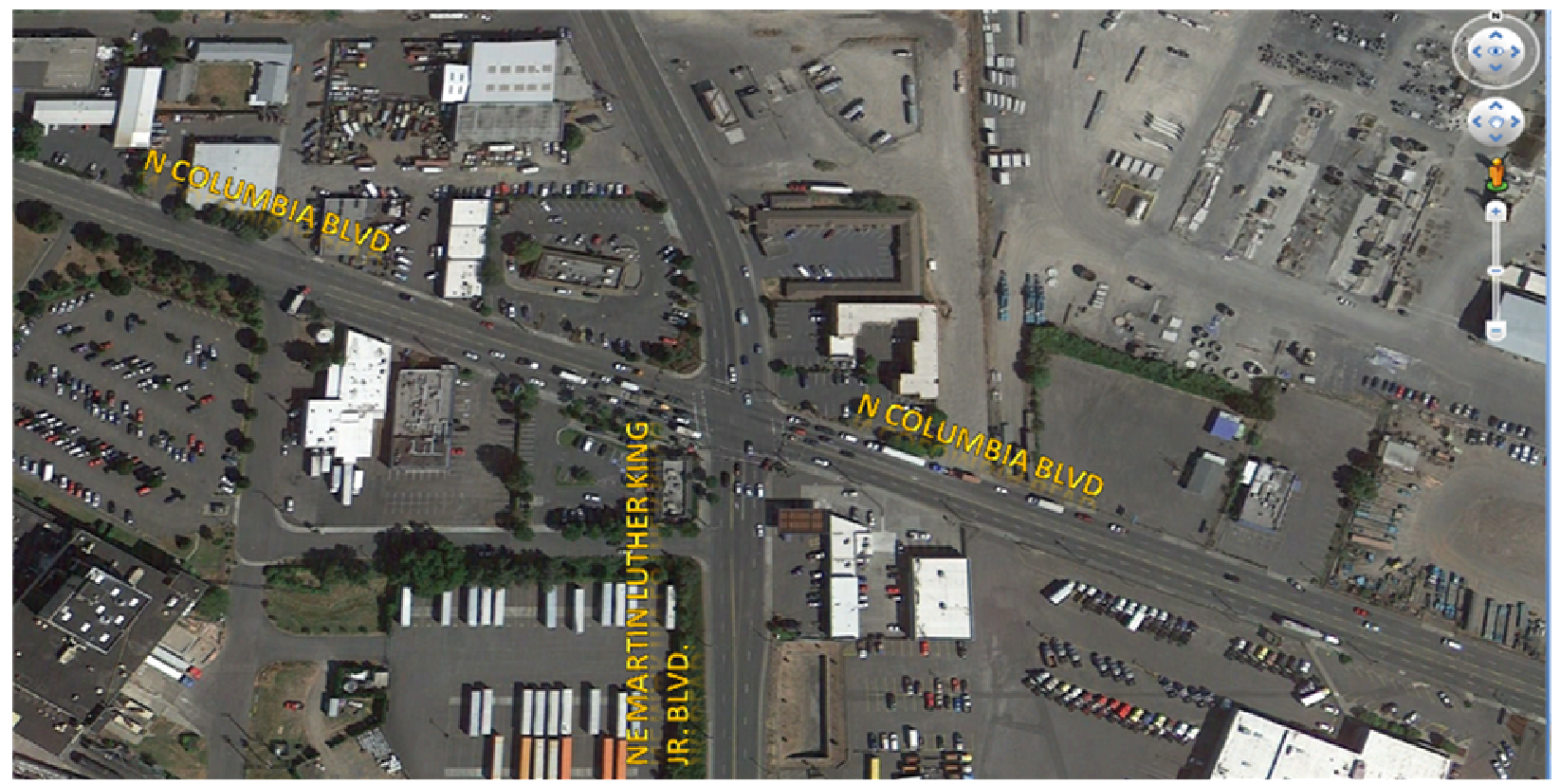

Figure 1: N Columbia Blvd and NE Martin Luther King Jr. Blvd Intersection

\subsection{Research Objectives}

The primary objective of this research is to evaluate the impact of freight priority signal at NE Martin Luther King Jr. Blvd and N Columbia Blvd intersection. Previous test bed implication of freight priority signal at Sulivan City, Texas as well as N Columbia Blvd and N Macrum Avenue in Portland has shown significant operational and safety benefits. Details of those test bed implication are provided in the literature review section. The study intersection has higher truck traffic compare to N Columbia Blvd and N Macrum Avenue intersection. Therefore, the intent of 
this study is to observe similar or more safety and pavement damage benefits than the previous implementations.

\subsection{Methodology}

Freight Priority system provides service that encourage to improve travel times for freight traffic and help industries to ensure reliable, faster, and more cost effective service. Usually faster running vehicles idle less and release smaller amounts of pollutants, which potentially results in cleaner air in the environment. In most cases priority has little impact on general traffic flow and is an inexpensive way to make freight more competitive with the automobiles. In general, priority is the preferential treatment of one vehicle class over another at a signalized intersection without causing the traffic signal controllers to drop from normal operations. Priority strategies provide priority treatment to a specific class vehicle following detection and subsequent priority request activation. Various types of priority strategies may be used if available within the traffic control environment such as early green (EG), which truncates the red time, or green extension (GE), which extends the green time, for the freight traffic when a priority equipped freight is approaching towards the intersection.

This study scoped to analyze TkSP by using VISSIM micro-simulation software to evaluate the strategic benefits of that priority logic in the existing system. Methodology mimicked the Texas Transportation Institution (TTI) field installation and also the City of Portland's field installation at N Columbia Blvd and N Macrum Avenue intersection. Detectors placed in the stop bars and up stream in the eastbound direction, up-stream detector classify the vehicles and communicate with the National Electrical Manufactures Association (NEMA) actuated controller in VISSIM. Based on signal status and vehicle actuation NEMA controller extend the green time to reduce hard break stop of truck traffic at the stop bar. Detector location and extension of green time is predefined based on existing clearance time on that approach and average truck speed. The classifier in the VISSIM obtains the actuations from the two pairs of loops on the eastbound approach and determines the vehicle class and speed. The vehicle classification and the speed of the vehicle are then communicated with the NEMA controller in VISSIM. Based on the signal status and the speed of the truck, the program extend the green time for that approach. 


\subsection{Organization of Report}

The structure of the report proceeds as follows. The introduction section details the importance of freight priority and its implication and evaluation. The literature review section explores previous implication of freight priority logic and strategies. Methodology chapter includes a detailed description of model development, assumptions, testing and calibration. The results and analysis of the simulation model is provided in the analysis chapter. Conclusion, study findings and future recommendations are presented in the conclusion section. 


\subsection{LITERAURE REVIEW}

This chapter will provide a brief review of truck priority signal, detail description of different field implementations and performance summary. This chapter also described various truck priority signal strategies and its implementation benefits.

Truck priority signal uses similar strategy as transit signal priority (TSP). In TSP priority is given to the transit to reduce travel time and delay but for truck, priority is given to reduce hard stops and red-light running. The two widely used TSP strategies are green time extension and early green time (red truncation). The green time extension is found to be the most useful for truck priority signal.

\subsection{Truck Priority Signal in Texas}

A brief review of truck priority signal system have been found that there are only few system deployed in the US as strategy. A system was deployed at a rural, isolated high-speed signal in Texas. The system was developed and implemented at one signalized intersection in Sullivan City, Texas in order to address the issues connected with the increased truck traffic and resulting pavement damage, traffic delay and decreased safety at a signalized intersection (Sunkari, Charara and Urbanik, 2001 [6]). Specifically, this system had an objective to minimize stops experienced by trucks at high-speed signalized intersections. It used loop detectors and a classifier to identify trucks approaching the intersection. This information was then used by an algorithm developed by the Texas Transportation Institute (TTI) to minimize truck stops and traffic delay while improving safety, reducing pavement wear, and decreasing traffic delay. The before-after analysis showed that the system would pay for itself in less than two years (Sunkari, Charara and Urbanik, 2001 [6]).

\subsection{Truck Priority Signal in Portland}

The priority system implemented in Portland, encouraged by what TTI accomplished in Texas, a similar truck priority system developed and implemented at N Columbia Blvd and N Macrum Avenue intersection. The main element of the system includes:

- Advance detection by lane (loop detectors); 
- Equipment that can determine and store approach vehicles speed and type (classification) at that advance point (the programmable logic controller);

- Decision logic that estimates arrival at the stop bar and how to modify the traffic controller's operation; and the intersection traffic controller.

From truck speed data, it was found that not all but a significant number of trucks passed thru the intersection with high speed and less number of stops. From the vehicular delay summary, it also shown that truck delay reduced significantly with priority (approximately $40 \%$ compare to without priority). And the green time distribution also shows with priority had more green time in the approach compare to without priority [5].

\subsection{Truck Priority Signal Benefits}

Benefits of implementing truck priority signals are correlated with vehicle operating and maintenance cost savings. Vehicle operating costs are a function of fuel consumption, tire use, maintenance and repair, oil use, capital depreciation, license and insurance costs, and operating labor costs (Berthelot et al, 1996 [7]). For a large truck to slow or stop at a traffic signal, then accelerate to free-flow speed, the primary increase in vehicle operating cost will be in the use of fuel and additional maintenance related activities. Fuel use is a function of the vehicle engine, transmission, and differential efficiency and the weight, size of the vehicle, and quality of fuel (Berthelot et al). Fuel savings could be modeled using detailed tools developed by industry (e.g. Freightliner) for their vehicles as applied to individual vehicles or by more aggregate models based on user costs (HERS, Micro Ben Cost, AASHTO Red Book). Alternatively, an average reduction in fuel use could be assumed. As an example, field operational tests at a weigh station determined that the average truck saved 1/3 gallon when allowed to bypass weigh stations in the Advantage I-75 ITS Field Operational Test (Maze et al, 1998 [8])

Another important element of truck priority signals benefit is the user cost saving. The user cost savings will be the value of the delay saved for each truck (which individually may be minor but collectively may be substantial). In general, the value of commercial vehicle time savings consists of the value of time savings for the driver, the vehicle and the cargo. The value of inventory costs is difficult to estimate accurately without specific knowledge of the value of the 
cargo. The value of time savings is typically calculated for differing sizes of commercial vehicles and differing types of carrier. The AASHTO User Benefit Analysis for Highways Manual [9] recommends that the hourly value of time for commercial vehicles be calculated as $100 \%$ of the prevailing wage rate of that industry and lists values from $\$ 20$ to $\$ 30$ per hour.

Truck priority signal strategy can improve safety while reducing crashes as well. From the Federal Highway Administration (FHWA) study, it was found that signalized intersection crashes make up $21 \%$ of all traffic crashes, and crashes at rural, high-speed signalized intersection tend to be more severe [10]. Many researchers have studied the problem and developed solutions with varying degrees of success. The probability of a crash at a signalized intersection is associated with the concept of dilemma zone, within which some drivers may decide to proceed, and some drivers may decide to stop. Some people define the dilemma zone as a physical zone on the through lane approaching the intersection, and some define it as a time interval before a vehicle enters the intersection. Accordingly, the signal timing strategies developed to reduce crashes at this type of intersection vary with the definition of the dilemma zone adopted. Such systems developed so far include Basic Green-Extension systems, Enhanced Green-Extension systems, and Green-Termination systems. All adaptive signal control systems require advance traffic detection some distance upstream of the intersection. Regardless of how the dilemma zone is defined, one should realize that it is a dynamic concept, and it varies with the speed and type (car or truck) of individual vehicle.

\subsection{New Strategies for Truck Priority Signal}

One solution developed by researchers from the Texas Transportation Institute (TTI) for isolated, rural, high-speed, signalized intersections is the Detection-Control System (D-CS) [11]. This system defines the dilemma zone as the time period between 5.5 and 2.5 seconds before a vehicle enters the intersection, it requires two loop detectors in a speed trap configuration be installed about $1000 \mathrm{ft}$ upstream of the intersection on the main approach. The system consists of three components - vehicle detection, D-CS control processor, and traffic control system; and it implements a 2-step gap-out strategy to reduce the possibility of sudden green phase termination by max out. Compared to the conventional multiple advance detector system, theoretical analysis

done by TTI researchers indicated that for the same maximum allowable headway (MAH) and maximum green, D-CS requires fewer detectors per through lane ( 2 vs. 3 or more) and is much 
less likely to experience max-out. Even though D-CS requires fewer detectors per lane, its installation cost may exceed that of multiple advance detector system due to the extra length of trenching and cabling. The strategy implemented in D-CS aims at reducing overall traffic delay, and minimizing truck stops and delays. It allows at most, one car, but no trucks, in the dilemma zone when the signal changes from green to yellow. Beginning in 2003, TTI researchers installed D-CS at 8 locations in Texas, they found that D-CS reduced crash by 39\%, and red-light violation by up to $70 \%$. They concluded that D-CS yielded a dollar benefit (from reduced crashes) of $\$ 55,000$, and a benefit-to-cost ratio of 15:1 per intersection per year [12]. 


\subsection{MICRO SIMULATION MODELING IN VISSIM}

This chapter will provide a brief overview of VISSIM micro simulation software and its parameters (driving parameter, network element, traffic flow and signal control strategy). This chapter also provide a detail description of traffic flow model, signal control model and network elements (key for model development) in VISSIM. A step by step process to develop VISSIM models for both existing and priority conditions are also described in this chapter. Finally simulation approach to this modeling also presented at the end of this chapter.

\subsection{VISSIM Model and Parameter}

VISSIM is a microscopic, time-step, and behavior-based simulation model developed in Karlsruhe, Germany to analyze the full range of functionally classified roadways and public transportation operations. VISSIM uses the Wiedemann car following model, which represents the psychological processes of the driver to obtain a desired following distance and relative speed to the lead vehicle. This model is very good at capturing the oscillatory behavior of drivers, which is a key determinant in roadway capacity. The car following model has several parameters which the user may adjust for calibration. Separate car following parameters may be applied to freeway sections, merge sections, and arterial streets. The VISSIM model was chosen because of its capabilities to simulate or modeling a wide variety of signal strategies, including transit signal priority.

\section{Model Description}

The VISSIM simulation package version 5.10 is used in this analysis, which has two integrated programs called traffic flow model and signal control model. The traffic flow model sends second by second detector information's to the signal control model. The signal control model uses this information to determine signal operation and re-send signal aspects to the traffic flow model. VISSIM then starts the next iteration of the traffic flow. Figure 2 represents the relationship between traffic flow model and signal control model. 


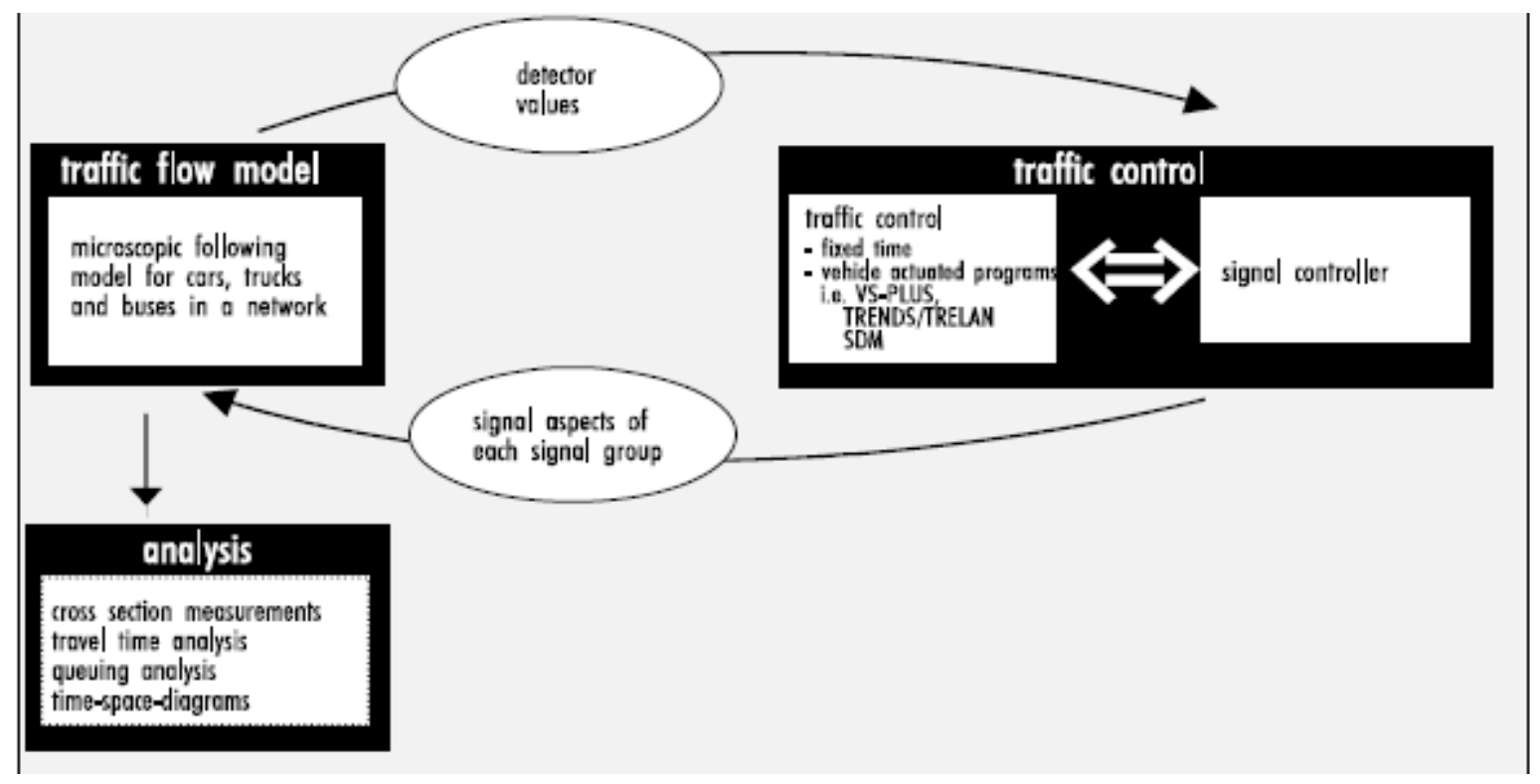

Figure 2: Communication between traffic simulator and signal state generator.

(VISSIM 5.10 User Manual [12])

\section{Description of the Traffic Flow Model}

The traffic flow model has two sub models called car-following model and lane-changing model.

The car-following model describes the movement of individual vehicles based on a

psychophysical driver behavior model developed by Wiedemann (1974). The basic component

behind this model is that the driver of a fast moving vehicle starts to decelerate when

approaching to a slower vehicle based on an individual perception threshold. Since the driver cannot determine the exact speed of the vehicle ahead, driver's speed will fall below that speed. The driver will then accelerate trying to adjust the speed to the vehicle ahead. This results in an interactive process of acceleration and deceleration as shown in the Figure 3 In that figure $S D V$, $C L D V, O P D V$ and $S D X$ are different thresholds and regimes in the Wiedemann 74 car-following model. 


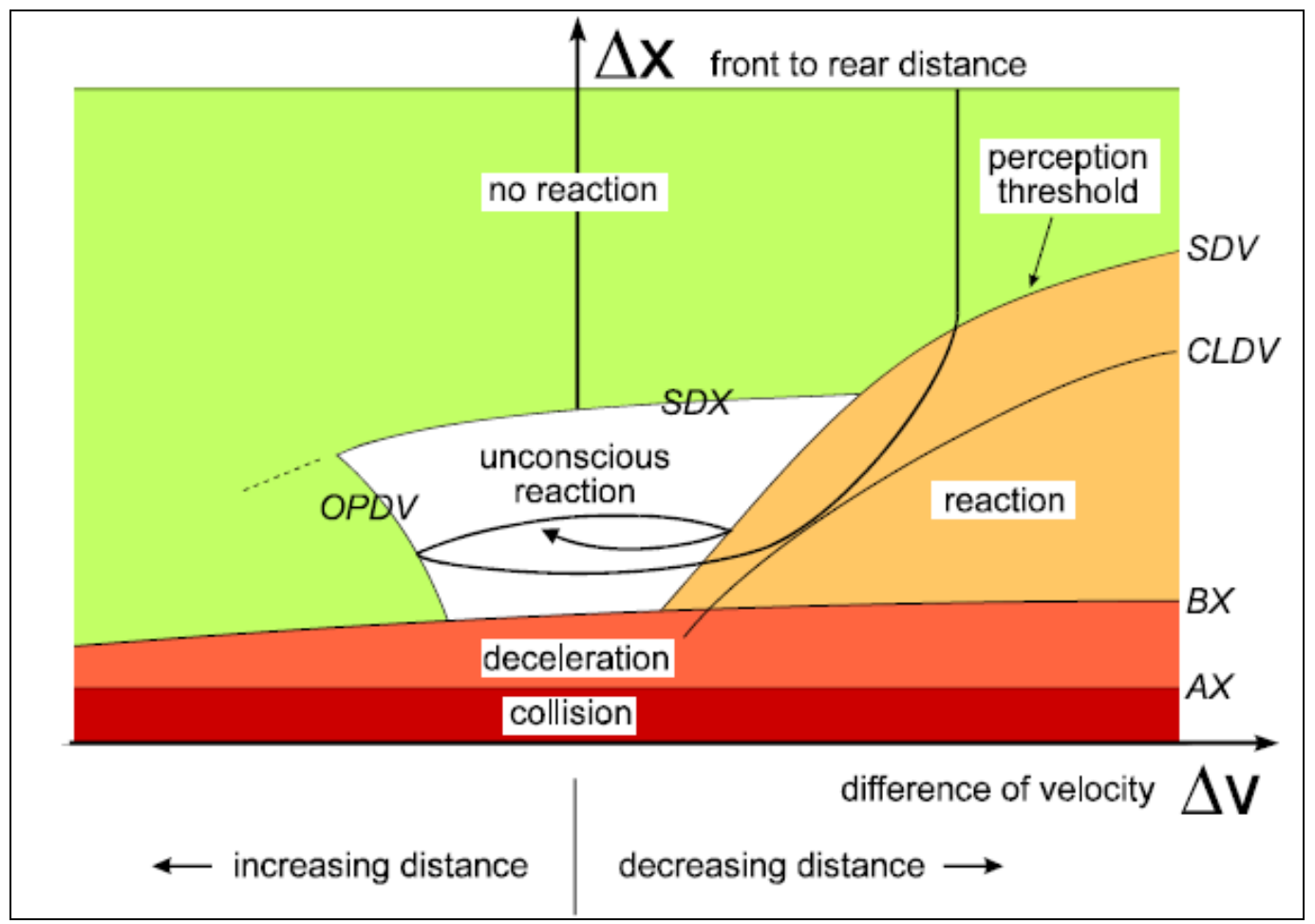

Figure 3: Interactive Process of Acceleration and Deceleration of moving vehicles.

(VISSIM user guide 5.10[13])

The lane-changing model operates through a complex set of rules, which mainly depends on the type of roadway environment (i.e. urban, freeway). The basic logic behind this sub model is based on the concept that a faster vehicle approaching to a slower one on the same lane, would check if it could improve its position by changing to an adjacent lane. In doing so, it takes into account of six other nearby vehicles at each second. Drivers on multiple lane roadway yield to preceding vehicles, but they also yield to adjacent vehicles when changing lanes. The following attributes characterize each driver-vehicle unit present in the simulation:

- Vehicle length

- Maximum speed

- Potential acceleration

- Actual position in the network

- Actual speed and acceleration

- Behavior of driver-vehicle unit 
- Psychophysical sensitivity thresholds of the driver (ability to estimate speed and distances, aggressiveness)

- Memory of the driver

- Acceleration based on current speed and the driver's desired speed

- Interdependence of driver-vehicle unit

- Reference to leading and following vehicles on own and adjacent lanes

- Reference to current link and next intersection

- Reference to next traffic signal.

\section{Description of the Signal Control Model}

Modeling signal operation in VISSIM achieved through the detection of vehicles or pedestrian by detectors, processing the logic by controller and display the signal by signal heads.

Signal Controller: The signal controller retains and executes the signal control logic. Signalized intersections can be modeled in VISSIM either using the built-in fixed-time control or an optional external signal state generator (e.g. optional module VAP). In VISSIM there are other signal control logic add-ons such as VSPLUS, TRENDS or Type 2070 VS-PLUS controller software. VISSIM can also be controlled externally through a serial interface to NEMA TS/2 controller or an Econolite ASC/3 controller and to a SCATS controller as well. In VISSIM every signal controller (SC) is represented by its individual SC number and signal groups (also referred to as signal phase) as its smallest control unit.

Signal Group and Signal Heads (Indicators): A signal head is the actual device showing the picture of the associated signal group. Signal heads are coded in VISSIM for each travel lane individually at the location of the signal stop line. Vehicles approaching an amber signal will proceed through the intersection if they cannot come to a safe stop in front of the stop bar. Signal indications are typically updated at the end of each simulation second. Signal head coding allows for the exact modeling of any kind of situation. This includes the ability to model different signal groups for different vehicle types on the same travel lane. For example, modeling a bus travelling in the mixed traffic but yielding to its own separate signal phase is possible with VISSSIM by selecting the appropriate vehicle classes for each signal head. 
Detectors: In field conditions vehicle/pedestrian detection is achieved using various methodologies including induction loops, video cameras, push buttons, track circuits etc. VISSIM models each detector type in the same way; a network element of user-defined length. A message impulse is transmitted to the signal controller as soon as a vehicle reaches the element with its front and another one when leaves it with its tail. Signal controller reads detector information for every time step, based on the detector information; it decides the status of the signal display during the subsequent time step.

VISSIM model also includes a programming language called vehicle actuated programming (VAP) that can be used to model the control logic of a signal controller. During a simulation run, VAP interprets the logic programmed by the user, and send the signal commands to the traffic flow model. At the same time, it interprets detector variables from the traffic flow model and adjusts the signal commands accordingly.

The signal head and detectors are the two main components link the traffic flow model with signal control model. In VISSIM signal controls are modeled by placing signal heads at the positions of the stop bars on the intersection. Signal head can be placed at any locations on the links or connectors, and during the simulation they will display the status of that signal control at each simulation second (green, amber, or red). Detectors measure the traffic for the signal control (i.e., gap, occupancy, and presence) and they are also used for microscopic and measurements (i.e., speeds, volume, and travel times)

\section{Network Elements}

Network is the hardware of VISSIM model and link is the main part of that hardware. Link represents single or multiple lane roadway segments. Connecting several links together creates a network and addition of several static and dynamic control and operational data make this network functional.

Static data remains unchanged during the simulation. It represents roadway infrastructure and includes:

- Directional roadway segments with a specific number of lanes (these are called links) 
- Connectors between links that replicate turning movements, lane drops, and lane additions

- Location and size of transit stops

- Positions of traffic signal and stop bars

- Positions and size of detectors

Dynamic data contains information to control or operate simulated traffic, it includes:

- Traffic volume for links entering the network

- Location of route decision points

- Priority rules to model un-signalized intersections and permissive left turns

- Location of stop signs

- Signal phasing and timing

The desired speed in urban areas does not derive directly from the technical data of a car but from the geometrical layout of the street and intersections. Usually the desired speed is reduced around intersections. Semi-compatible movements are modeled via gap acceptance. The values of gap acceptance and waiting positions are user defined.

\subsection{Model Development}

To evaluate the truck priority logic, existing field condition was modeled in the study intersection; a base model (existing field condition) was developed to mimic the field situation. To develop the base model, field geometric data, traffic data and traffic control data was required in addition to the VISSIM software. Here is the list specific field data acquired to develop the base model with their source.

\section{Existing Model}

A model is a prototype of field conditions in a smaller scale, following field information of the study intersection were used to develop the base model in VISSIM.

- Aerial photograph (scaled) for the study intersection (N Columbia Blvd and NE Martin Luther King Jr. Blvd). 
- Existing peak hour turning movement volume and heavy vehicle percentages for both Mid Day and PM peak hours from the City of Portland.

- Detail signal timing information, including force-offs, clearance, intervals, and detector information from the City of Portland.

- Intersection configuration, and posted speed limit from Google map and field visit.

- Peak Hour Factors (PHF) calculated for the turning movement counts.

The step by step process followed through the development of base VISSIM model described below.

\section{Step 1 (Network Development)}

The first step of building a model is to create the network from a scaled bitmaps. To simulate exact operation in VISSIM, it is necessary to replicate the modeled infrastructure network to an appropriate scale. VISSIM allows the following file types for scaled background:

- Import a scaled network form other applications such as VISSUM, CROSSIG, P2 or other applications that supported VISSIM.

- Import a scaled network from the signal control optimization software's Synchro.

- Base maps or drawings as a background so that the VISSIM network can be traced exactly according to a scaled map.

A scaled Google map was used as a background for coding the study intersection, an iterative process applied to the background map for proper scaling. A scaled background is the key for correct lane width, taper length and storage lengths. In a scaled background several links are traced, and looked for all of the approaches of the intersection and determined the number of lanes both on the approach and within the intersection. Links are then connected with the connectors to make the turns at the intersection.

\section{Step 2 (Traffic Control)}

Once the network is coded with links and connectors in VISSIM, the next step is to provide the traffic controls at the intersection. Primary control of the study intersection is signal but for the permissive cases study intersection is coded with priority rules. The posted speed limits are 
provided by the speed decisions and as necessary lower speed areas are coded with reduced speed areas. The details about the signal control are explained earlier. Field signal timing information of the study intersection was provided in the VISSIM model through the NEMA controller. Figure 4 below showing an example of the NEMA controller in VISSIM for base signal timing coding

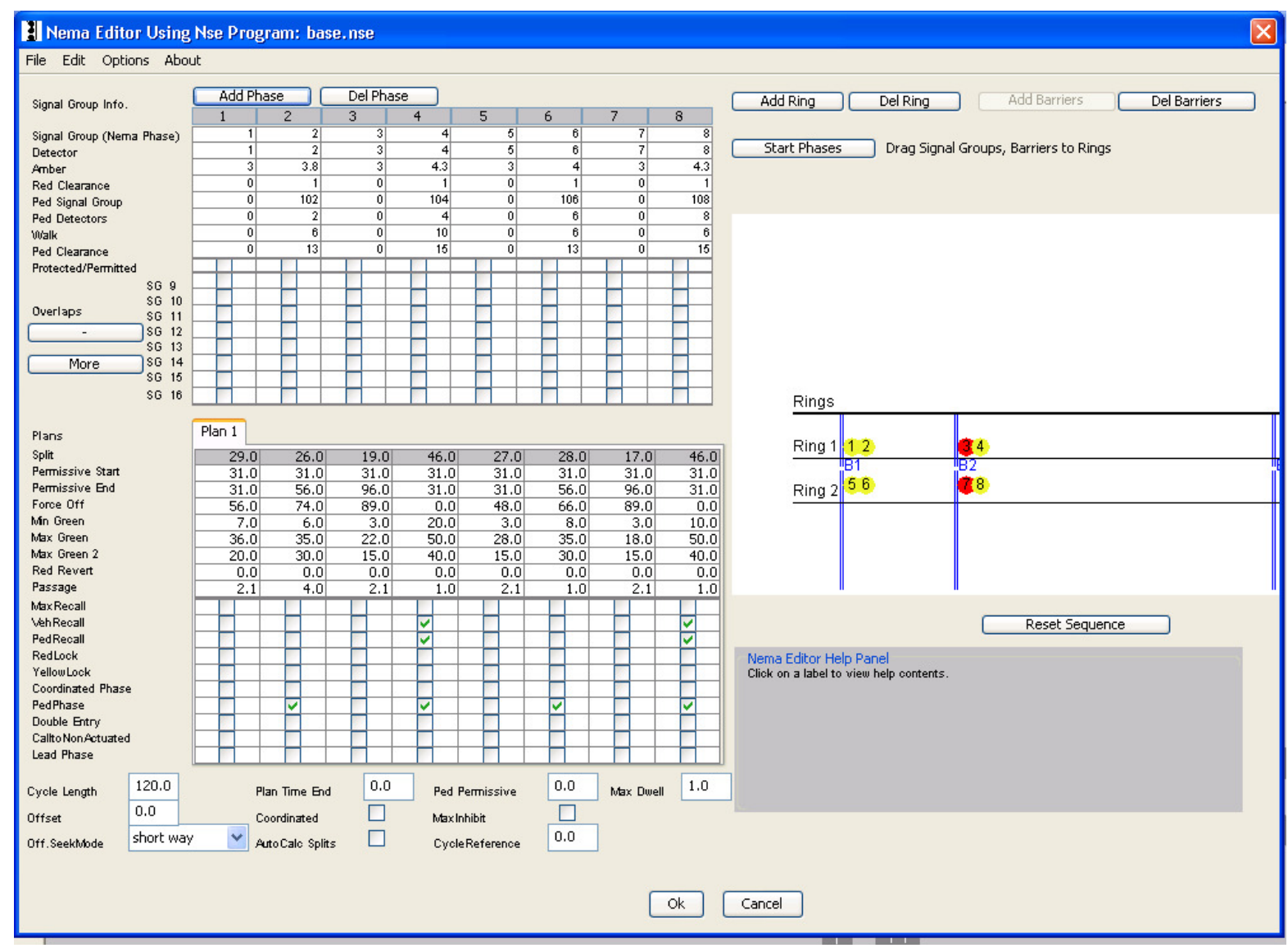

Figure 4: Example of NEMA Signal Controller in VISSIM for Base Signal Coding. 


\section{Step 3 (Route Guidance)}

The next step in the model development is to provide the route guidance for the approach vehicles. A route is a fixed sequence of links and connectors

- From, the routing decision point (red cross-section)

- To, at least one destination point (green cross-section).

Each routing decision point can have multiple destinations resembling a tree with multiple branches. A route can have any length - from a turning movement at a single junction to a route that stretches throughout the entire VISSIM network. A routing decision affects only vehicles of a class that is contained in the routing decision and not having any routing information. If a vehicle already has a route assigned to it then it first has to pass its destination point (green bar) prior to be able to receive new routing information. Based on the existing peak hour turning movement counts, route decisions (percentage of total approach volume making left, thru and right turns) are estimated.

\section{Step 4 (Volume Input)}

Once the route decisions are provided, the network is ready for the input volume. Table 4.3.1 in this report provided peak hour turning movement volumes and heavy vehicle percentages for the study intersection. In VISSIM there are several different ways to provide the input traffic in the network. The static input of total vehicles associated with car and truck composition percentages for each approach were applied for this study. So the VISSIM models need to have traffic composition setup as well as vehicle classes to be used for each approach. Based on the existing heavy vehicle percentages, traffic compositions were created for each approach. Input vehicle at the start of the link was provided by using the approach composition. Now the model is ready to run and collect the output results, data collector should be provided prior to run the model. Data collectors are provided to collect speed, volume, travel time, queue length and delay for each vehicle classes. Figure 5 bellow shows an example of existing base model setup in VISSIM for the study intersection. 


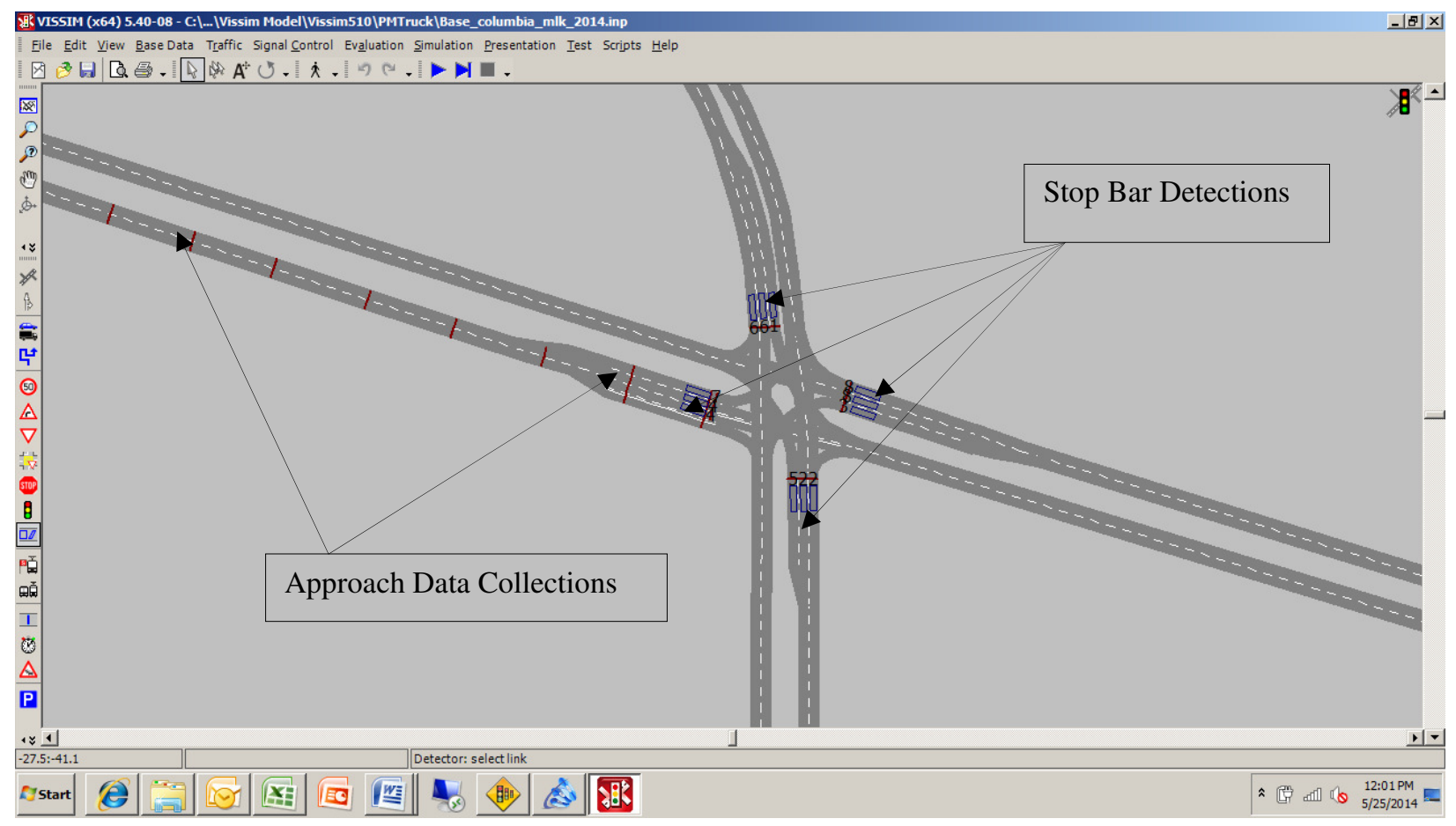

Figure 5: Example of Base Model Setup in VISSIM for the Study Intersection

\section{Truck Priority Model}

Truck priority model developed from the base model, which was calibrated and validated for the existing field conditions. As discussed earlier the theory of truck priority in this analysis is to extend the green time for the study approach depending on truck speed and call time. So the primary modifications in the build scenario would be to adjust signal timing and provide advance loop detections at appropriate location on the approach.

A sensitivity test of the VISSIM model is required to identify the best location and amount of green time extension needed. For $40 \mathrm{mph}$ average truck speed in the eastbound approach of the study intersection required to have advance loops around 650 (40 $\mathrm{mph}^{*} 1.47 * 11$ seconds) feet upstream of the stop bar with 11 seconds of green time extension. Advance detectors in the model are provided the same way as stop bar detectors and the green time extension is adjusted in the NEMA controller. Figure 6 shows an example of truck priority signal model setup in VISSIM for the study intersection. 


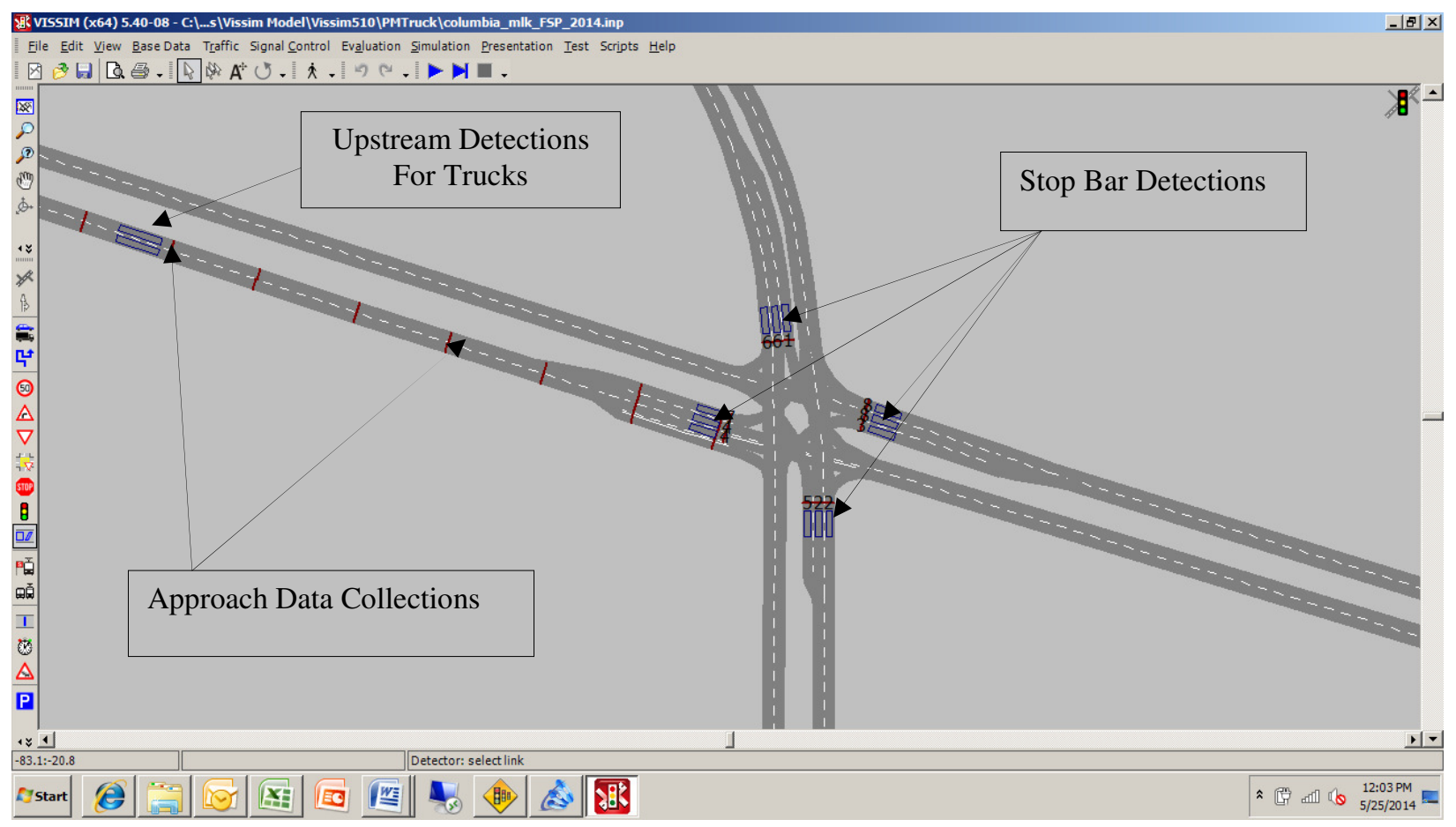

Figure 6: Example of Truck Priority Model Setup in VISSIM for the Study Intersection.

Passage time for the through phase of the eastbound approach was extended to 11 seconds, leaving default time for all other phases. A hold would be placed if the eastbound approach receives a call from upstream truck detectors during the green indication and before the extension maxed out. Figure 7 below showing an example of NEMA signal controller in VISSIM for truck priority signal coding. 


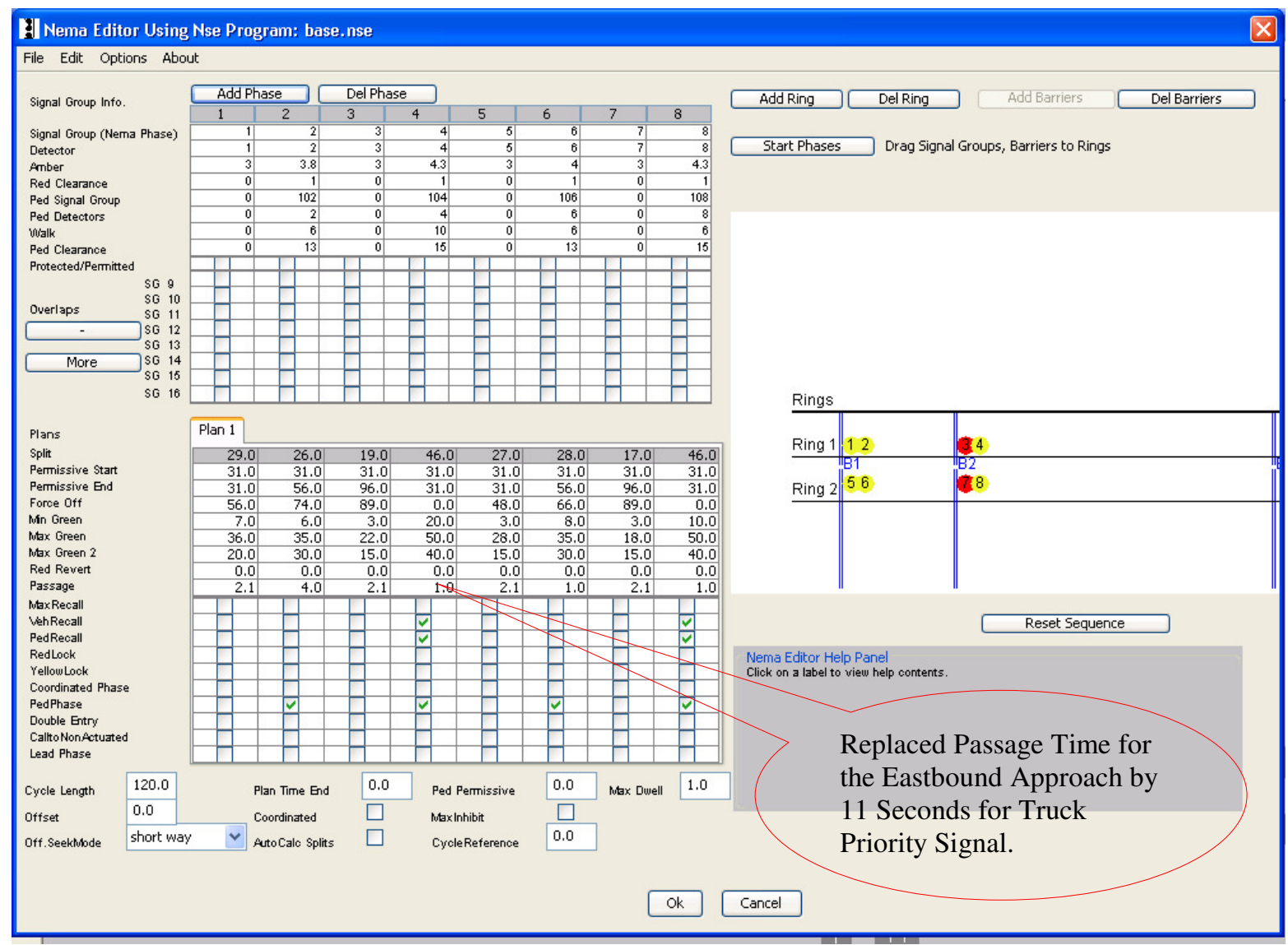

Figure 7: Example of NEMA Signal Controller in VISSIM for Truck Priority Signal Coding.

\subsection{Simulation Approach}

In this study truck priority signal was evaluated in two step process. The first step was to build and calibrate the base model for existing conditions and then the calibrated and validated base model was used to develop and simulate truck priority signal by modifying signal timing and providing advance loop detections in the approach. Before and after analysis of truck priority logic was used to compare the changes of speed, delay, travel time, green time extension and number of stops for both car and truck traffic along the approach where preferential treatment was applied. Additionally, the model provided an excellent tool to observe the overall behavior of traffic and the impact on major and minor streets when truck priority applied. For output results average of ten random seed runs results were used for this study. 


\subsection{TRAFFIC OPERATION ANALYSIS}

This chapter will provide detailed traffic operation analysis for this study; it includes describing existing field conditions, validation of existing filed conditions in VISSIM and detailed analysis of truck priority scenarios in VISSIM

\subsection{Existing Operation Data}

Existing filed operations data of the study intersection was used to calibrate and validate existing base VISSIM model, and to compare truck priority signal operations. During the study periods, the City of Portland did not have any field performance data other than turning movements count and signal timings. So for this study we developed SYNCHRO models for existing filed conditions. Primary intend of the SYNCHRO models were to obtain filed performances quickly and accurately, which also verified with field observations and data collections. The Table 4.1.1 and Figure 8 show existing base performances from the SYNCHRO models for both PM and Mid Day periods.

Table 4.1.1 - Existing Intersection Performances for PM peak and Mid Day Periods

\begin{tabular}{|c|c|c|c|c|c|c|}
\hline & & $\begin{array}{l}\text { Eastbound } \\
\text { Approach }\end{array}$ & $\begin{array}{l}\text { Westbound } \\
\text { Approach }\end{array}$ & $\begin{array}{c}\text { Northbound } \\
\text { Approach }\end{array}$ & $\begin{array}{c}\text { Southbound } \\
\text { Approach }\end{array}$ & Intersection \\
\hline \multirow{3}{*}{ 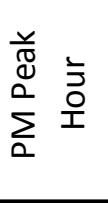 } & Delay (seconds/vehicle) & 29 & 34 & 29 & 28 & 30 \\
\hline & Level of Services (LOS) & $\mathrm{C}$ & $\mathrm{C}$ & $\mathrm{C}$ & $\mathrm{C}$ & $\mathrm{C}$ \\
\hline & $\begin{array}{l}\text { 95th Percentile Queue } \\
\text { Length (feet) }\end{array}$ & 280 & 390 & 180 & 190 & - \\
\hline \multirow{3}{*}{ 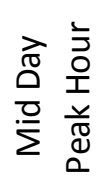 } & Delay (seconds/vehicle) & 23 & 24 & 32 & 31 & 27 \\
\hline & Level of Services (LOS) & $\mathrm{C}$ & $\mathrm{C}$ & $\mathrm{C}$ & $\mathrm{C}$ & $\mathrm{C}$ \\
\hline & $\begin{array}{l}\text { 95th Percentile Queue } \\
\text { Length (feet) }\end{array}$ & 165 & 220 & 170 & 165 & - \\
\hline
\end{tabular}




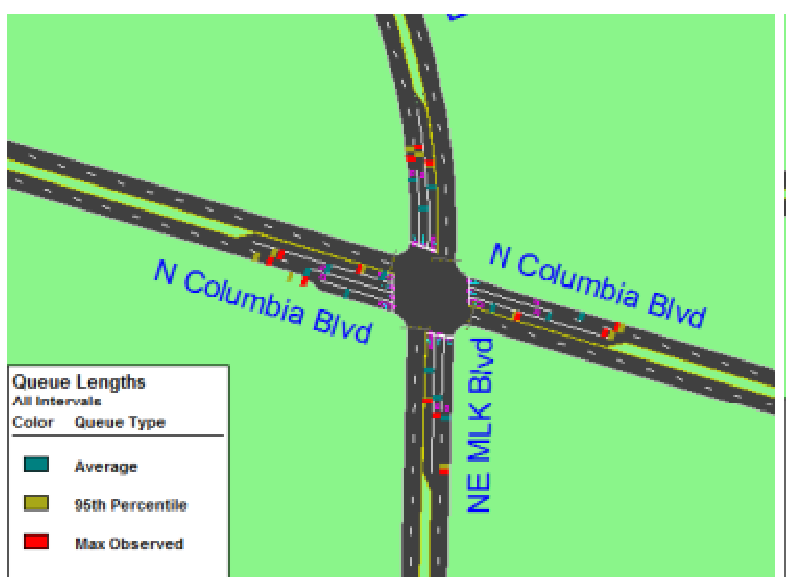

Mid Day SYNCHRO Model

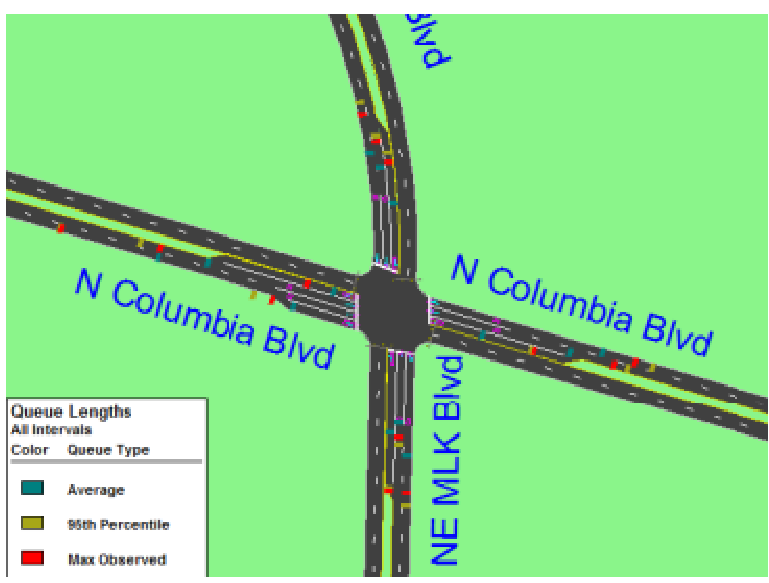

PM Peak SYNCHRO Model

Figure 8: Existing Base SYNCHRO Models

Based on filed verification of the study intersection it was confirmed that approach queue length for both PM and Mid Day periods are closely match with the SYNCHRO model outputs. Table 4.1.2 shows a comparison of approach queue length, filed counts vs. SYNCHRO model outputs 
Table 4.1.2 - Queue Length Field Count vs. SYNCHRO Model Output.

\begin{tabular}{|c|c|c|c|c|c|c|c|c|c|}
\hline \multirow{2}{*}{ Date } & \multirow{2}{*}{ Time } & \multicolumn{4}{|c|}{ SYNCHRO Models Queue (feet)** } & \multicolumn{4}{|c|}{ Queue Length From Field (feet)* } \\
\hline & & EB Thru & WB Thru & NB Thru & SB Thru & EB Thru & WB Thru & NB Thru & SB Thru \\
\hline $10 / 23 / 2008$ & $11: 20 \mathrm{AM}$ & \multirow{6}{*}{165} & \multirow{6}{*}{220} & \multirow{6}{*}{175} & \multirow{6}{*}{165} & 320 & 240 & - & - \\
\hline $10 / 23 / 2008$ & $11: 25 \mathrm{AM}$ & & & & & - & - & 160 & 160 \\
\hline $10 / 23 / 2008$ & 11:31 AM & & & & & 200 & 300 & - & - \\
\hline $10 / 23 / 2008$ & 11:37 AM & & & & & - & - & 220 & 280 \\
\hline $10 / 23 / 2008$ & $11: 40$ AM & & & & & 120 & 300 & - & - \\
\hline $10 / 23 / 2008$ & 11:45 AM & & & & & - & - & 100 & 160 \\
\hline & Average & 165 & 220 & 175 & 165 & 213 & 280 & 160 & 200 \\
\hline
\end{tabular}

\begin{tabular}{|c|c|c|c|c|c|c|c|c|c|}
\hline \multirow{2}{*}{ Date } & \multirow{2}{*}{ Time } & \multicolumn{4}{|c|}{ SYNCHRO Models Queue (feet)** } & \multicolumn{4}{|c|}{ Queue Length From Field (feet)* } \\
\hline & & EB Thru & WB Thru & NB Thru & SB Thru & EB Thru & WB Thru & NB Thru & SB Thru \\
\hline $10 / 23 / 2008$ & $4: 20 \mathrm{PM}$ & \multirow{6}{*}{280} & \multirow{6}{*}{390} & \multirow{6}{*}{180} & \multirow{6}{*}{190} & 280 & 360 & - & - \\
\hline $10 / 23 / 2008$ & 4:27 PM & & & & & - & - & 220 & 160 \\
\hline $10 / 23 / 2008$ & $4: 32 \mathrm{PM}$ & & & & & 300 & 340 & - & - \\
\hline $10 / 23 / 2008$ & 4:40 PM & & & & & - & - & 160 & 300 \\
\hline $10 / 23 / 2008$ & 4:45 PM & & & & & 320 & 480 & - & - \\
\hline $10 / 23 / 2008$ & 4:48 PM & & & & & - & - & 260 & 220 \\
\hline & Average & 280 & 390 & 180 & 190 & 300 & 393 & 213 & 227 \\
\hline
\end{tabular}

Note:

* Field queue lengths are based on actual field counts, assumed an average of $20^{\prime}$ for car and $40^{\prime}$ for truck length

** SYNCHRO queue lengths are from model output

The base VISSIM model developed earlier in the model development chapter was used to calibrate and validate existing traffic operations of the study intersection. The intent of the study was to evaluate truck priority logic during high truck traffic in the Mid-Day and low truck traffic in the PM peak hour. Performance matrices in the Table 4.1.1 were used as target to calibrate and validate existing base VISSIM models of the study intersection.

Existing field signal timings are coded in the VISSIM models through NEMA controllers shown in Figure 4. The existing VISSIM models then run for an hour of operation with 15-minutes seeding time for both Mid-Day and PM peak hour models.

\subsection{Calibration and Validation of Existing Conditions}

Calibration of the model is an important process in the methodology because it provides credibility to the results by closely representing actual field conditions. Typical calibration measures consist of volume, delay, LOS, travel time and queue length. In this study delay, LOS 
and queue lengths were used as calibration measures. The base VISSIM models of the study intersection were coded with "Urban Motorized" link type and Wiedemann 74 car-following driving behavior parameters. The default value of the driving behavior parameters and ten-step simulation resolutions parameter in VISSIM provided realistic and close match of the existing driving conditions. Table 4.2.1 and Table 4.2.2 provided field validation of existing base VISSIM model results.

Table 4.2.1 - Existing Intersection Delay and Level of Services: Field vs VISSIM Model Output.

\begin{tabular}{|c||c|c|c|c|}
\hline \multirow{3}{*}{ Direction } & \multicolumn{2}{c|}{ Mid Day Peak Hour } & \multicolumn{2}{c|}{ PM Peak Hour } \\
\cline { 2 - 5 } & Existing Target & Existing VISSIM & Existing Target & Existing VISSIM \\
\cline { 2 - 5 } & LOS/Delay (sec/veh.) & LOS/Delay (sec/veh.) & LOS/Delay (sec/veh.) & LOS/Delay (sec/veh.) \\
\hline \hline EB & C (23) & C (22) & C (29) & C (27) \\
\hline WB & C (24) & C (20) & C (34) & C (31) \\
\hline NB & C (32) & C (25) & C (29) & C (27) \\
\hline SB & C (31) & C (20) & C (28) & C (26) \\
\hline Intersection & C (27) & C (25) & C (30) & C (30) \\
\hline
\end{tabular}

Table 4.2.2 - Existing Intersection Queue: Field vs VISSIM Model Output.

\begin{tabular}{|c||c|c|c|c|}
\hline \multirow{2}{*}{ Direction } & \multicolumn{2}{|c|}{ Mid Day Peak Hour } & \multicolumn{2}{c|}{ PM Peak Hour } \\
\cline { 2 - 5 } & Existing Target & Existing VISSIM & Existing Target & Existing VISSIM \\
\cline { 2 - 5 } & Queue Length (feet) & Queue Length (feet) & Queue Length (feet) & Queue Length (feet) \\
\hline \hline EB & 165 & 180 & 280 & 270 \\
\hline WB & 220 & 230 & 390 & 370 \\
\hline NB & 170 & 170 & 180 & 200 \\
\hline SB & 165 & 180 & 190 & 210 \\
\hline
\end{tabular}

From the above tables it was observed that existing VISSIM model outputs are reasonably close to the target (field) values in terms of delay, LOS and queue length during both PM peak and Mid Day periods. So no further adjustment was necessary to the driving behavior parameters assuming the models are well calibrated for the base conditions. Calibrated VISSIM models were then used for truck priority signal operations.

\subsection{Truck Priority Scenario Analysis}

To implement truck priority signal, base VISSIM models were used for consistency and authenticity of the results. For sensitivity, an additional scenario was created from the PM peak hour model called "PM peak hour with higher truck traffic". The new scenario has everything similar to PM peak hour model but with higher truck traffic in the study approach (eastbound 
direction). For the new scenario traffic composition of the eastbound approach was modified with higher truck percentage. Existing PM peak hour model had 9\% truck traffic in the eastbound approach; the new scenario assumed $20 \%$ truck traffic in the same approach. Table 4.3.1 shows turning movement volume and heavy vehicle percentages for the new scenario. The new scenario was also modeled for both base and priority conditions. Both base and priority scenarios had similar output matrices (MOE's). Detector locations and existing lane configurations are shown in Figure 3.5

Table 4.3.1 - Intersection Turning Movement Volumes and Heavy Vehicle Percentages:

\begin{tabular}{|c|c|c|c|c|c|c|c|}
\hline \multirow{2}{*}{$\begin{array}{l}\text { Approach } \\
\text { Direction }\end{array}$} & \multirow{2}{*}{ Turning Movements } & \multicolumn{2}{|c|}{ PM Peak Hour } & \multicolumn{2}{|c|}{ Mid-Day } & \multicolumn{2}{|c|}{$\begin{array}{c}\text { PM Peak Hour With More } \\
\text { Truck }\end{array}$} \\
\hline & & $\begin{array}{l}\text { Total Volume } \\
\text { (vph) }\end{array}$ & $\begin{array}{c}\text { Heavy } \\
\text { Vehicle \% }\end{array}$ & $\begin{array}{c}\text { Total Volume } \\
\text { (vph) }\end{array}$ & $\begin{array}{c}\text { Heavy } \\
\text { Vehicle \% }\end{array}$ & $\begin{array}{c}\text { Total Volume } \\
\text { (vph) }\end{array}$ & $\begin{array}{c}\text { Heavy } \\
\text { Vehicle \% }\end{array}$ \\
\hline \multirow{3}{*}{ 吕 } & Eastbound Left & 49 & \multirow{3}{*}{$9 \%$} & 28 & \multirow{3}{*}{$19 \%$} & 49 & \multirow{3}{*}{$20 \%$} \\
\hline & Eastbound Thru & 624 & & 361 & & 624 & \\
\hline & Eastbound Right & 192 & & 111 & & 192 & \\
\hline \multirow{3}{*}{$\sum_{3}^{m}$} & Westbound Left & 105 & \multirow{3}{*}{$8 \%$} & 66 & \multirow{3}{*}{$17 \%$} & 105 & \multirow{3}{*}{$8 \%$} \\
\hline & Westbound Thru & 633 & & 399 & & 633 & \\
\hline & Westbound Right & 169 & & 107 & & 169 & \\
\hline \multirow{3}{*}{$\stackrel{q}{z}$} & Northbound Left & 86 & \multirow{3}{*}{$7 \%$} & 79 & \multirow{3}{*}{$11 \%$} & 86 & \multirow{3}{*}{$7 \%$} \\
\hline & Northbound Thru & 314 & & 287 & & 314 & \\
\hline & Northbound Right & 85 & & 78 & & 85 & \\
\hline \multirow{3}{*}{$\stackrel{\mathscr{\omega}}{\omega}$} & Southbound Left & 213 & \multirow{3}{*}{$5 \%$} & 177 & \multirow{3}{*}{$8 \%$} & 213 & \multirow{3}{*}{$5 \%$} \\
\hline & Southbound Thru & 373 & & 310 & & 373 & \\
\hline & Southbound Right & 34 & & 28 & & 34 & \\
\hline
\end{tabular}




\subsection{RESULTS SUMMARY}

This chapter summarizes and compares VISSIM model outputs for base cases and truck priority scenarios. Key MOE's for this analysis were delay, LOS, green time distribution, and speed data. MOE's are collected separately for the intersection and for the eastbound approach, for all vehicles as well as for truck traffic only. This chapter also provides a detail statistical analysis of the key MOE outputs to assess significance of performance differences between the base and truck priority implication. The VISSIM models were run for an hour and 15 minutes allowing 15 minutes seeding time and the outputs were collected from the last hour of each simulation run. An average of 10 VISSIM simulations runs having 10 different random seed results were reported in this study.

\subsection{Truck Speed Analysis}

Truck speed data is an important and key measure to evaluate truck signal priority implications. In the simulation model, truck volume and truck speed data were collected at every 100 feet interval along the approach direction of truck priority signal implementations. Table 5.1 presents the total number of trucks in the eastbound approach passing the intersection without any stop. Figure 9 and 10 shows an example of truck speed in the eastbound approach of the study intersection. Figure 9 for base case (no priority) and Figure 10 for truck priority. In Figure 10, it shows that a significant number of trucks move through the intersection without stopping compare to Figure 9, Table 5.1.1 shows the total number of trucks passing through the intersection without making any stop.

Table 5.1.1 - Total Number of Trucks Not Stopped in the Eastbound Approach

\begin{tabular}{|l|c|c|}
\hline \multirow{2}{*}{ Scenario } & \multicolumn{2}{|c|}{$\begin{array}{c}\text { No of Truck Pass the } \\
\text { Intersection Without Any Stop } \\
\text { (vph) }\end{array}$} \\
\cline { 2 - 3 } & Base Case & Priority Case \\
\hline PM Peak Hours & 29 & 60 \\
\hline Mid Day Peak Hours & 6 & 60 \\
\hline PM Peak Hour with More Trucks & 76 & 116 \\
\hline
\end{tabular}




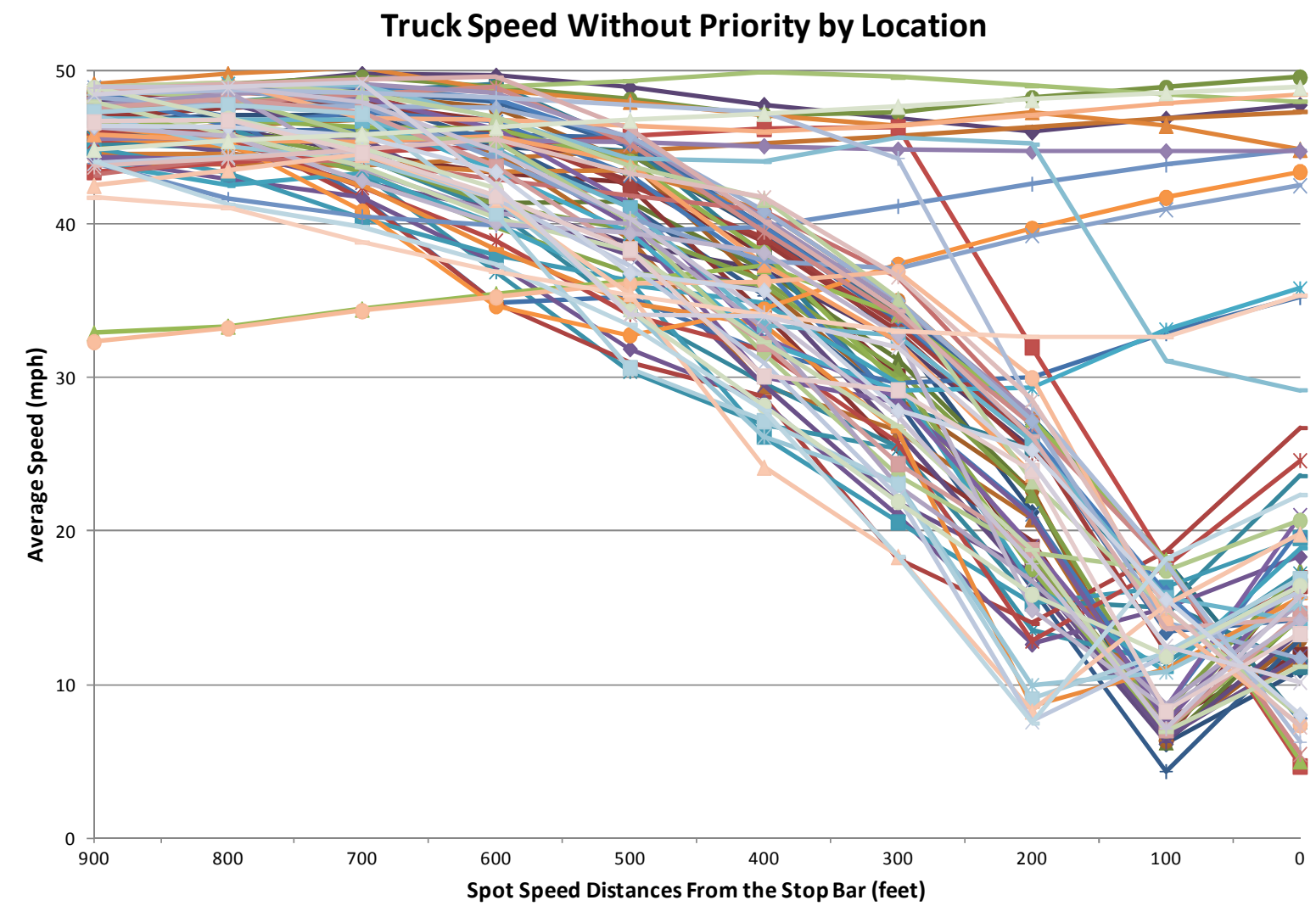

Figure 9: Truck Speed Profiles Base Case (PM Peak Hour) 


\section{Truck Speed With Priority by Location}

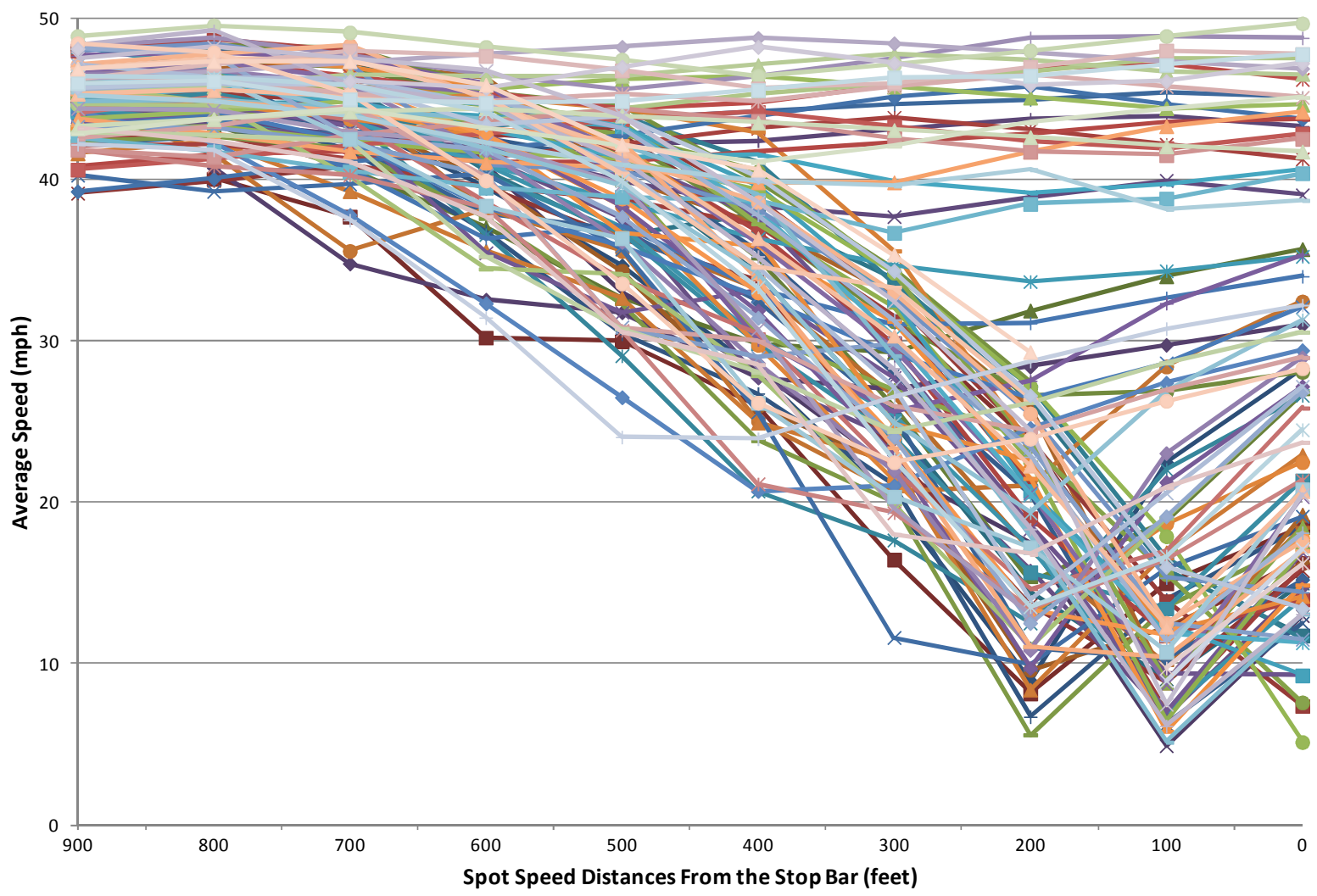

Figure 10: Truck Speed Profiles Priority Case (PM Peak Hour)

These trajectories were grouped into three classifications: trucks that were provided an extension, trucks that proceeded through without an extension (arrived during minimum green, arrived during yellow, etc), and those that were stopped. Figure 11 shows this summary of truck speeds. In this simple analysis of truck priority logic (that only extends for trucks), not every truck receives an extension and its potential benefits. There are a variety of reasons for the traffic signal not being able to provide an extension: phase may be timing its minimum green; there may not be a call on a conflicting phase; the phase may already be on yellow or red; or the truck phase has reached its maximum green. There are also a large percentage of the trucks that will not need an extension at this location, because the conflicting traffic volumes (Side Street and main street left turn) are low. Figure 11 also shows that truck speeds (in the simulation model) are not significantly affected by the traffic signal until approximately 600 feet before the signal where drivers begin to react to the signal indication. As a result, truck speeds at greater than 600 
feet from the stop bar are only indicative of the randomly distributed speed assigned to each vehicle in the model.

\section{Truck Speed Profiles}

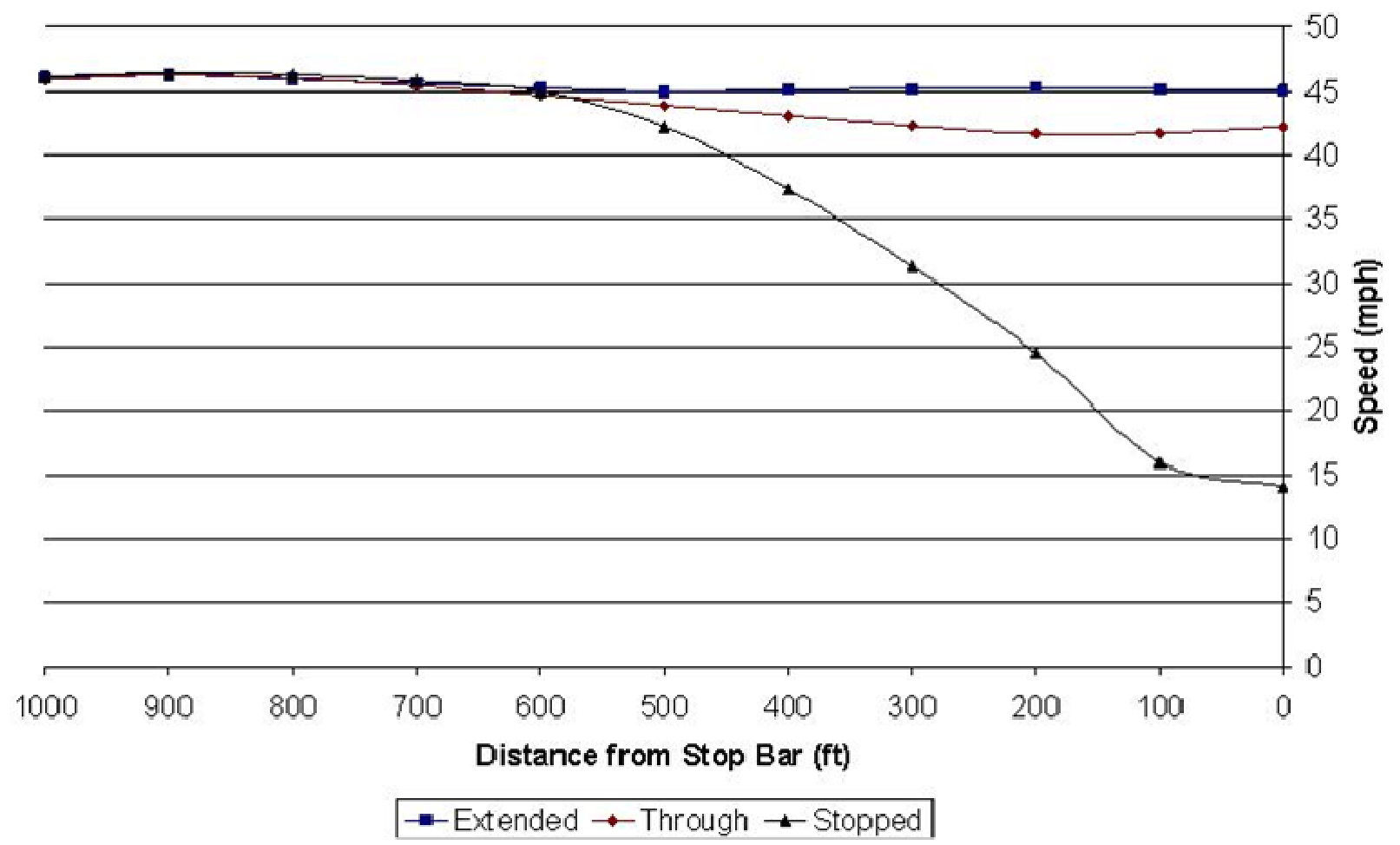

Figure 11: Truck Speed Profiles (Grouped Higher Volume Scenario)

A summary of the truck speed profiles without truck priority are provided in Figure 12. It also shows that the average truck speed of the stopped vehicles is lower without truck priority, which indicates that the vehicles that some of the trucks that received an extension were removed from the "stopped" category. 


\section{Truck Speed Profiles}

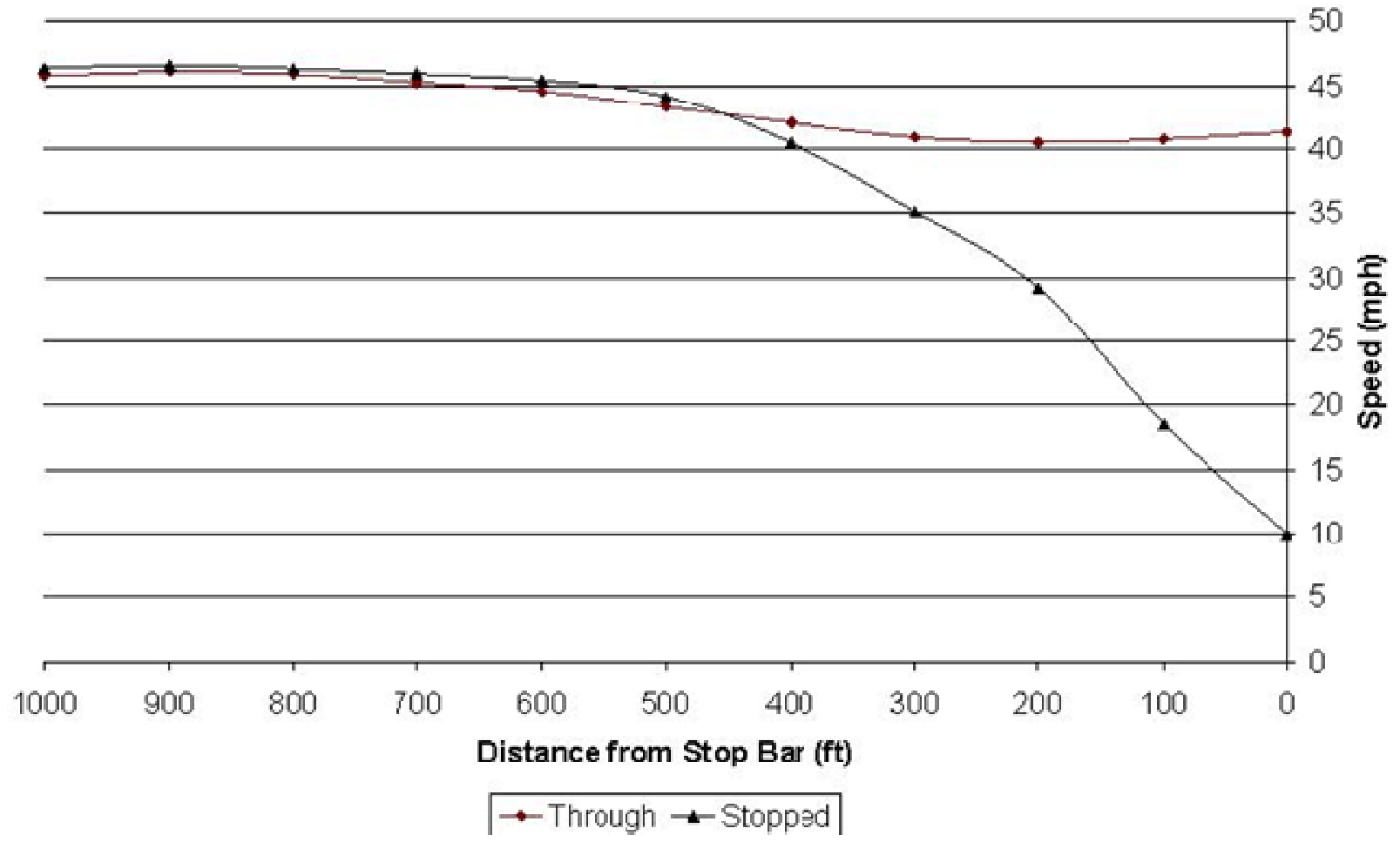

Figure 12: Truck Speed Profiles (Without Priority)

\subsection{Green Time Distribution}

In this study green time distribution is another key measure to compare with and without truck priority scenarios. The green time distribution was collected for both eastbound through and eastbound left turns for all three scenarios as shown in the Table 5.2.1. From that table, with priority scenario received longer green time compare to without priority scenario. These differences are significant for Mid Day and PM Peak Hours with More Truck scenarios. For better understanding of the results, statistical analysis was done to see whether these differences are statistically significant or not. 
Table 5.2.1 - Average Green Time Distribution Comparison

\begin{tabular}{|c|c|c|c|c|c|c||}
\hline \hline \multirow{2}{*}{ Signal Phase } & \multicolumn{2}{|c|}{ PM Peak Hour } & PM Peak with More Truck & \multicolumn{2}{c|}{ Mid Day Hour } \\
\cline { 2 - 8 } & \hline $\begin{array}{c}\text { Without } \\
\text { Truck } \\
\text { Priority }\end{array}$ & $\begin{array}{c}\text { With } \\
\text { Priority }\end{array}$ & $\begin{array}{c}\text { Without } \\
\text { Truck } \\
\text { Priority }\end{array}$ & $\begin{array}{c}\text { With } \\
\text { Priority }\end{array}$ & $\begin{array}{c}\text { Without } \\
\text { Truck } \\
\text { Priority }\end{array}$ & $\begin{array}{c}\text { With } \\
\text { Priority }\end{array}$ \\
\cline { 2 - 8 } & (sec) & (sec) & (sec) & (sec) & (sec) & (sec) \\
\hline \hline Eastbound Left Turn & 6.27 & 6.48 & 6.70 & 7.07 & 5.83 & 5.82 \\
\hline Eastbound Thru & 27.87 & 28.05 & 28.61 & 31.70 & 26.50 & 28.13 \\
\hline
\end{tabular}

Table 5.2.2 - Average Green Time Distribution Statistics

\begin{tabular}{|c|c|c|c|c|c|c|c|}
\hline \multirow{2}{*}{ Dir. } & \multirow{2}{*}{ Statistics } & \multicolumn{2}{|c|}{ PM Peak Hour } & \multicolumn{2}{|c|}{ PM Peak with More Truck } & \multicolumn{2}{|c|}{ Mid Day Hour } \\
\hline & & Base & Priority & Base & Priority & Base & Priority \\
\hline \multirow{5}{*}{ 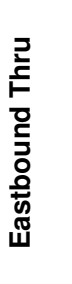 } & Average Green Time (sec.) & 27.87 & 28.05 & 28.62 & 31.70 & 26.50 & 28.13 \\
\hline & Standard Deviation & 0.42 & 0.75 & 1.03 & 1.03 & 0.29 & 0.79 \\
\hline & Sample Size & 10 & 10 & 10 & 10 & 10 & 10 \\
\hline & T-Stat & \multicolumn{2}{|c|}{0.66} & \multicolumn{2}{|c|}{6.68} & \multicolumn{2}{|c|}{6.10} \\
\hline & P-Value & \multicolumn{2}{|c|}{0.5249} & \multicolumn{2}{|c|}{+0.0001} & \multicolumn{2}{|c|}{+0.0002} \\
\hline \multirow{5}{*}{ 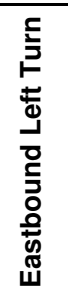 } & Average Green Time (sec.) & 6.27 & 6.48 & 6.70 & 7.07 & 5.83 & 5.82 \\
\hline & Standard Deviation & 0.368 & 0.377 & 0.665 & 0.442 & 0.519 & 0.437 \\
\hline & Sample Size & 10 & 10 & 10 & 10 & 10 & 10 \\
\hline & T-Stat & \multicolumn{2}{|c|}{1.26} & \multicolumn{2}{|c|}{1.46} & \multicolumn{2}{|c|}{0.05} \\
\hline & P-Value & \multicolumn{2}{|c|}{0.2391} & \multicolumn{2}{|c|}{0.1770} & \multicolumn{2}{|c|}{0.9638} \\
\hline
\end{tabular}

In statistical analysis, both the T-Test and P-Value results are measures to identify statistical significance of the results between the date sets. In this study for small sample size, two tired TTest was done for 95 percent confidence interval. Hypothesis was tested here assuming that $\mathrm{H}_{0=}$ $\mathrm{H}_{\mathrm{a}}\left(\mathrm{H}_{0}=\right.$ means are equal, $\mathrm{H}_{\mathrm{a}}=$ means are different). P-value represents smallest level of significance between the data set. P-value lower than 0.05 considered significant differences $\left(\mathrm{H}_{0}\right.$ rejected) but P-value 0.05 and higher considered insignificant differences in the results between the alternatives. In table 5.2.2, green time distribution results shows significant difference for eastbound through traffic only, during Mid Day and PM Peak Hours with More Truck scenarios. 


\subsection{Delay Analysis}

Delay is another key measures collected for all three scenarios, as shown in Table 5.3.1. From that table, truck delay was reduced significantly in the eastbound approach, while all vehicles delay was equal or slightly reduced. Table 5.3.1 also shows that average intersection delay for truck traffic reduced significantly for PM Peak Hour with More Truck scenario while slightly improved for other scenarios. A summary can be drawn from the Table 5.3.1 that higher truck or low volume intersection has more benefits for truck priority.

Table 5.3.1 - Average Vehicular Delay Comparison

\begin{tabular}{|c|c|c|c|c|c|c|}
\hline \multirow{3}{*}{ Direction of Travel } & \multicolumn{2}{|c|}{ PM Peak Hour } & \multicolumn{2}{|c|}{ PM Peak with More Truck } & \multicolumn{2}{|c|}{ Mid Day Hour } \\
\hline & $\begin{array}{l}\text { Without } \\
\text { Truck } \\
\text { Priority }\end{array}$ & $\begin{array}{c}\text { With } \\
\text { Priority }\end{array}$ & $\begin{array}{l}\text { Without } \\
\text { Truck } \\
\text { Priority }\end{array}$ & $\begin{array}{l}\text { With } \\
\text { Priority }\end{array}$ & $\begin{array}{l}\text { Without } \\
\text { Truck } \\
\text { Priority }\end{array}$ & $\begin{array}{c}\text { With } \\
\text { Priority }\end{array}$ \\
\hline & $(\mathrm{sec})$ & $(\mathrm{sec})$ & (sec) & $(\mathrm{sec})$ & (sec) & (sec) \\
\hline EB All Vehicles & 27 & 27 & 28 & 26 & 22 & 20 \\
\hline EB Truck Only & 32 & 28 & 33 & 26 & 26 & 20 \\
\hline Intersection All Vehicles & 30 & 30 & 29 & 29 & 25 & 25 \\
\hline Intersection Truck Only & 37 & 36 & 35 & 31 & 29 & 28 \\
\hline
\end{tabular}

Table 5.3.2 - Average Stopped Delay Comparison

\begin{tabular}{|c|c|c|c|c|c|c|}
\hline \multirow{3}{*}{ Direction of Travel } & \multicolumn{2}{|c|}{ PM Peak Hour } & \multicolumn{2}{|c|}{ PM Peak with More Truck } & \multicolumn{2}{|c|}{ Mid Day Hour } \\
\hline & $\begin{array}{l}\text { Without } \\
\text { Truck } \\
\text { Priority }\end{array}$ & $\begin{array}{l}\text { With } \\
\text { Priority }\end{array}$ & $\begin{array}{l}\text { Without } \\
\text { Truck } \\
\text { Priority }\end{array}$ & $\begin{array}{l}\text { With } \\
\text { Priority }\end{array}$ & $\begin{array}{l}\text { Without } \\
\text { Truck } \\
\text { Priority }\end{array}$ & $\begin{array}{c}\text { With } \\
\text { Priority }\end{array}$ \\
\hline & (sec) & (sec) & (sec) & $(\mathrm{sec})$ & (sec) & (sec) \\
\hline EB All Vehicles & 18 & 17 & 17 & 16 & 13 & 12 \\
\hline EB Truck Only & 15 & 12 & 15 & 11 & 11 & 8 \\
\hline Intersection All Vehicles & 20 & 20 & 19 & 19 & 17 & 17 \\
\hline Intersection Truck Only & 20 & 19 & 18 & 16 & 14 & 14 \\
\hline
\end{tabular}

Average stopped delay data was collected from the simulation runs for all three scenarios, as shown in Table 5.3.2. It shows in the table that all vehicles stopped delay either equal or slightly reduced but truck delay reduced significantly, especially in the eastbound approach. Same as delay data, average stopped delay for truck priority scenario is lower than that of without priority and more truck make the difference even larger. Average number of stops estimated as number of stops per vehicles showing in Table 5.3.3. They are not different than others, average number 
of stops reduced in the priority scenario, reduction is more significant for truck vehicles compare to all vehicles, and similarly eastbound approach is significant compare to over all intersection. Also more truck scenario has the highest reduction of average number of stops.

Table 5.3.3 - Average Number of Stops Comparison (Stops/Vehicle)

\begin{tabular}{|c|c|c|c|c|c|c|}
\hline \multirow[b]{2}{*}{ Direction of Travel } & \multicolumn{2}{|c|}{ PM Peak Hour } & \multicolumn{2}{|c|}{ PM Peak with More Truck } & \multicolumn{2}{|c|}{ Mid Day Hour } \\
\hline & $\begin{array}{l}\text { Without } \\
\text { Truck } \\
\text { Priority }\end{array}$ & With Priority & $\begin{array}{c}\text { Without } \\
\text { Truck } \\
\text { Priority }\end{array}$ & With Priority & $\begin{array}{c}\text { Without } \\
\text { Truck } \\
\text { Priority }\end{array}$ & With Priority \\
\hline EB All Vehicles & 0.68 & 0.67 & 0.67 & 0.63 & 0.59 & 0.55 \\
\hline EB Truck Only & 0.62 & 0.56 & 0.63 & 0.54 & 0.53 & 0.45 \\
\hline Intersection All Vehicles & 0.70 & 0.70 & 0.69 & 0.68 & 0.65 & 0.64 \\
\hline Intersection Truck Only & 0.67 & 0.67 & 0.67 & 0.61 & 0.59 & 0.57 \\
\hline
\end{tabular}

Table 5.3.4 - Average Delay and Average Number of Stops Statistics for Eastbound Approach

\begin{tabular}{|c|c|c|c|c|c|c|c|c|c|}
\hline \multirow{2}{*}{\begin{tabular}{|c|} 
Time \\
of Day
\end{tabular}} & \multirow{2}{*}{ Measure of Effectiveness (MOE's) } & \multicolumn{2}{|c|}{ Average Data } & \multicolumn{2}{|c|}{ Sample Size } & \multicolumn{2}{|c|}{ Standardeviation } & T-Stat & P-Value \\
\hline & & Base & Priority & Base & Priority & Base & Priority & \begin{tabular}{l|l} 
Base & Priority
\end{tabular} & \begin{tabular}{l|l} 
Base & Priority \\
\end{tabular} \\
\hline \multirow{6}{*}{$\begin{array}{l}\text { 초 } \\
\text { 离 } \\
0 \\
0 \\
\sum_{0}\end{array}$} & Avg. Delay for Vehicles (veh/sec) & 27.07 & 226.56 & $=10$ & 10 & 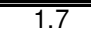 & 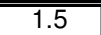 & 0.71 & 0.632 \\
\hline & \begin{tabular}{|l} 
Avg. Delay for Truck (veh/sec) \\
\end{tabular} & 31.96 & 27.63 & 10 & 10 & 4.1 & 4.2 & 2.34 & 0.044 \\
\hline & Avg. Stopped Delay for Vehicles (veh/sec) & 17.66 & 17.38 & 10 & 10 & 1.2 & 1.2 & 0.52 & 0.615 \\
\hline & Avg. Stopped Delay for Truck (veh/sec) & 15.38 & 12.31 & 10 & 10 & 3.0 & 2.3 & 2.55 & +0.031 \\
\hline & Avg. \# of Stops for Vehicles (stops/veh) & 0.68 & 0.67 & 10 & 10 & 0.0 & 0.0 & 0.54 & 0.600 \\
\hline & Avg. \# of Stops for Truck (stops/veh) & 0.62 & 0.56 & 10 & 10 & 0.1 & 0.1 & 1.59 & 0.145 \\
\hline & & & & & & & & & \\
\hline \multirow{6}{*}{ 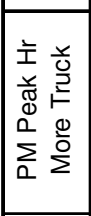 } & Avg. Delay for Vehicles (veh/sec) & 28.18 & 26.08 & 10 & 10 & 2.0 & 0.9 & 3.10 & +0.013 \\
\hline & Avg. Delay for Truck (veh/sec) & 32.76 & 26.51 & 10 & 10 & 2.6 & 2.5 & 5.48 & +0.000 \\
\hline & Avg. Stopped Delay for Vehicles (veh/sec) & 16.52 & 15.55 & 10 & 10 & 1.4 & 0.8 & 1.94 & 0.084 \\
\hline & Avg. Stopped Delay for Truck (veh/sec) & 15.31 & 11.47 & 10 & 10 & 2.0 & 1.8 & 4.51 & +0.001 \\
\hline & Avg. \# of Stops for Vehicles (stops/veh) & 0.67 & 0.63 & 10 & 10 & 0.0 & 0.0 & 3.61 & +0.006 \\
\hline & Avg. \# of Stops for Truck (stops/veh) & 0.63 & 0.54 & 10 & 10 & 0.0 & 0.1 & 4.11 & +0.003 \\
\hline & & & & & & & & & \\
\hline & Avg. Delay for Vehicles (veh/sec) & 22.18 & 20.47 & 10 & 10 & 0.8 & 2.0 & 2.53 & +0.032 \\
\hline 초 & Avg. Delay for Truck (veh/sec) & 25.65 & 20.36 & 10 & 10 & 1.9 & 2.8 & 5.01 & +0.001 \\
\hline $\bar{\sigma}$ & Avg. Stopped Delay for Vehicles (veh/sec) & 13.34 & 12.22 & 10 & 10 & 0.9 & 1.5 & 2.06 & 0.070 \\
\hline ص & Avg. Stopped Delay for Truck (veh/sec) & 11.25 & 7.64 & 10 & 10 & 1.2 & 1.4 & 6.18 & +0.000 \\
\hline 을 & Avg. \# of Stops for Vehicles (stops/veh) & 0.59 & 0.55 & 10 & 10 & 0.0 & 0.0 & 2.45 & +0.037 \\
\hline & Avg. \# of Stops for Truck (stops/veh) & 0.53 & 0.45 & 10 & 10 & 0.0 & 0.1 & 3.55 & +0.006 \\
\hline
\end{tabular}


Table 5.3.5 - Average Delay and Average Number of Stops Statistics for the

Intersection

\begin{tabular}{|c|c|c|c|c|c|c|c|c|c|}
\hline \multirow{2}{*}{$\begin{array}{l}\text { Time } \\
\text { of Day }\end{array}$} & \multirow{2}{*}{ Measure of Effectiveness (MOE's) } & \multicolumn{2}{|c|}{ Average Data } & \multicolumn{2}{|c|}{ Sample Size } & \multicolumn{2}{|c|}{ Standardeviation } & T-Stat & P-Value \\
\hline & & Base & Priority & Base & Priority & Base & Priority & \begin{tabular}{l|l} 
Base & Priority \\
\end{tabular} & \begin{tabular}{l|l} 
Base & Priority
\end{tabular} \\
\hline \multirow{6}{*}{ 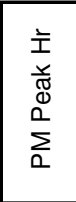 } & Avg. Delay for Vehicles (veh/sec) & 29.77 & 29.53 & 10 & 10 & 1.2 & $=1.0$ & 0.49 & 0.639 \\
\hline & \begin{tabular}{|l} 
Avg. Delay for Truck (veh/sec) \\
\end{tabular} & 36.77 & 35.78 & 10 & 10 & 2.3 & 3.2 & 0.81 & 0.439 \\
\hline & Avg. Stopped Delay for Vehicles (veh/sec) & 20.49 & 20.33 & 10 & 10 & 1.0 & 0.8 & 0.39 & 0.702 \\
\hline & Avg. Stopped Delay for Truck (veh/sec) & 19.98 & 19.15 & 10 & 10 & 1.8 & 2.2 & 0.93 & 0.378 \\
\hline & Avg. \# of Stops for Vehicles (stops/veh) & 0.70 & 0.70 & 10 & 10 & 0.0 & 0.0 & 0.32 & 0.753 \\
\hline & Avg. \# of Stops for Truck (stops/veh) & 0.67 & 0.67 & 10 & 10 & 0.0 & 0.0 & 0.30 & 0.773 \\
\hline & & & & & & & & & \\
\hline \multirow{6}{*}{ 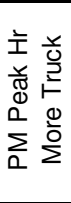 } & Avg. Delay for Vehicles (veh/sec) & 28.55 & 28.58 & 10 & 10 & 0.9 & 0.5 & 0.10 & 0.926 \\
\hline & Avg. Delay for Truck (veh/sec) & 35.28 & 31.43 & 10 & 10 & 1.9 & 2.0 & \multirow{2}{*}{$\begin{array}{l}4.49 \\
1.60\end{array}$} & +0.002 \\
\hline & Avg. Stopped Delay for Vehicles (veh/sec) & 18.88 & 19.31 & 10 & 10 & 0.7 & 0.4 & & 0.143 \\
\hline & Avg. Stopped Delay for Truck (veh/sec) & 17.99 & 15.77 & 10 & 10 & 1.5 & 1.6 & 3.20 & +0.011 \\
\hline & Avg. \# of Stops for Vehicles (stops/veh) & 0.69 & 0.68 & 10 & 10 & 0.0 & 0.0 & 2.56 & +0.030 \\
\hline & Avg. \# of Stops for Truck (stops/veh) & 0.67 & 0.61 & 10 & 10 & 0.0 & 0.0 & 6.18 & +0.000 \\
\hline & & & & & & & & & \\
\hline \multirow{6}{*}{ 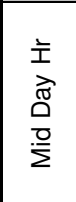 } & Avg. Delay for Vehicles (veh/sec) & 25.36 & 25.20 & 10 & 10 & 0.5 & 0.9 & 0.45 & 0.665 \\
\hline & \begin{tabular}{|l} 
Avg. Delay for Truck (veh/sec) \\
\end{tabular} & 29.38 & 28.12 & 10 & 10 & 1.4 & 1.5 & 1.92 & 0.087 \\
\hline & Avg. Stopped Delay for Vehicles (veh/sec) & 16.57 & 16.58 & 10 & 10 & 0.5 & 0.8 & 0.05 & 0.964 \\
\hline & Avg. Stopped Delay for Truck (veh/sec) & 14.06 & 13.57 & 10 & 10 & 1.0 & 0.9 & 1.18 & 0.268 \\
\hline & Avg. \# of Stops for Vehicles (stops/veh) & 0.65 & 0.64 & 10 & 10 & 0.0 & 0.0 & 1.80 & 0.106 \\
\hline & \begin{tabular}{|l|} 
Avg. \# of Stops for Truck (stops/veh) \\
\end{tabular} & 0.59 & 0.57 & 10 & 10 & 0.0 & 0.0 & 1.83 & 0.101 \\
\hline
\end{tabular}

A detail statistical analysis was done for average delay, average stop delay and average number of stops for both eastbound approach and overall intersection as shown in Table 5.3.4 and Table 5.3.5. In those tables T-test and P-values were estimated to evaluate statistical significance of the results between Base and Truck Priority scenarios. As mentioned earlier, P-value lowers than 0.05 signifies the differences. From Table 5.3.4, eastbound approach showing significant difference of the results during Mid Day and PM Peak Hours with More Truck scenarios. During peak hours, only truck vehicle class showing significant difference of the results. From table 5.3.5, overall intersection results are not significantly different except for truck vehicle class during PM Peak Hours with More Truck scenarios. 


\subsection{CONCLUSION \& RECOMMENDATION}

This study focused on analyzing the impacts of truck priority signal on truck traffics as well as on all vehicles at the study intersection.. The major categories of impacts were considered as follows:

1. Effect on Truck Operations and Reliability

2. Effect on Total Traffic Stream

\section{Effect on Roadway Pavement}

\section{Safety Impacts}

Within these categories, a verity of indicators was considered, and the most appropriate measures of effectiveness were chosen to evaluate the potential impacts of truck priority to truck traffics and to other non-truck traffic. Based on the simulation analysis results from Table 3.3.1, Table 5.3.2 and Table 5.3.3 the following conclusions are drawn:

- Priority may contribute to improved truck operations and its service reliability. When priority was provided, $13 \%$ to $21 \%$ improvements occurred in the travel delay and $20 \%$ to $32 \%$ improvements occurred in the stopped delay at major truck moving direction.

- Priority may contribute to improved operations and service reliability for all vehicles in the major truck travel direction. When priority was provided, $0 \%$ to $8 \%$ improvements occurred in the travel delay and $2 \%$ to $9 \%$ improvements occurred in the stopped delay for all vehicles at major truck moving direction.

- Priority may also improve carbon emission and reduce pavement damage (reducing hard stop of heavy vehicles) by reducing total number of stops by $1 \%$ to $7 \%$ for all vehicles and $9 \%$ to $16 \%$ for trucks only at major truck moving direction.

- Provision of priority resulted in improved truck travel delay and reduced number of stops with little to no negative impacts on all traffic at the intersection. 
- With above all improvements, priority should enhance safety along the eastbound approach and for the intersection as a whole.

This study can serve as groundwork for the evaluation of truck signal priority for agencies and researcher, future research can build upon this effort. Areas identified for future research include the provision of priority on truck leading approach on a coordinated signal system network; testing other priority strategies; combination of emergency preemption and freight preemption; monetary and environmental benefit from priority received network. 


\subsection{REFERENCES}

1. U.S. Department of Transportation (USDOT), Federal Highway Administration (FHWA), "Freight Analysis Framework" 2002a.

2. Commodity Flow Forecast Update and Lower Columbia River Cargo Forecast, prepared for the Port of Portland et al, by DRI-WEFA, BST and Cambridge Systematics, Inc., June 2002.

3. City of Portland, "Sustainable Freight Strategy Report and Recommendations", City of Portland Bureau of Transportation, October 20122.

4. Economic Development Research Group, "The Cost of Congestion to the Economy of the Portland Region", Portland Business Alliance 2006.

5. C. Monsere (2008), "Evaluating Traffic Signal Improvements For Freight Movement", Intelligent Transportation Lab, Portland State University.

6. Sunkari, S. R., Charara, H., \& Urbanik, T., II. (2001),” Minimizing Truck Stops at High-Speed Rural Signalized Intersections", ITE 2001 Annual Meeting and Exhibit (pp. 11), Institute of Transportation Engineers 1099 14th Street, NW Washington, DC.

7. Berthelot, C. F., Sparks, G. A., Blomme, T., Kajner, L., and Nickeson, M. (1996). "Mechanistic-Probabilistic Vehicle Operating Cost Model," Journal of Transportation Engineering, 122(5), pp. 337-341.

8. Maze, T.H., C. Monsere, M. Hancock, D. Plazak, B. McCall, "Electronic Screening in the I35 Corridor. In Transportation Quarterly", Volume 52, Number 1, EnoTransportation Foundation, Landsdowne, Virginia, Winter 1998.

9. AASHTO, A Manual of User Benefit Analysis for Highways, 2nd Edition, 2003

10. U.S. Department of Transportation (USDOT), Federal Highway Administration (FHWA), " Safety at Signalized Intersection " Presentation slide 24.

11. Bonneson, J, D. Middleton, K. Zimmerman, H. Charara. "Intelligent Detection-Control system for High Speed Rural Signalized Intersections", Report 4022-2, Texas Transportation Institute, August 2002.

12. Wei Zhang, "Field Evaluation of Detection Control System (D-CS)",Turner Fairbank Highway Research Center, National Rural ITS Conference, 2006.

13. VISSIM User Guide 5.10 